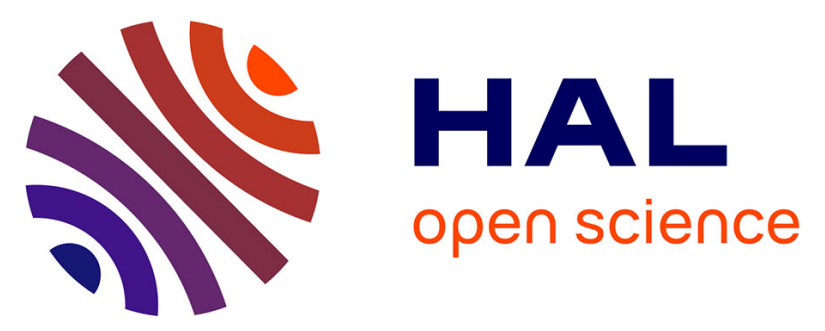

\title{
L'occupation du bassin de Neuwied (Rhénanie centrale, Allemagne) par les Magdaléniens et les groupes à Federmesser (aziliens)
}

Martin Street, Frank Gelhausen, Sonja Grimm, Frank Moseler, Laura Niven, Martina Sensburg, Elaine Turner, Stefan Wenzel, Olaf Jöris

\section{To cite this version:}

Martin Street, Frank Gelhausen, Sonja Grimm, Frank Moseler, Laura Niven, et al.. L'occupation du bassin de Neuwied (Rhénanie centrale, Allemagne) par les Magdaléniens et les groupes à Federmesser (aziliens). Bulletin de la Société préhistorique française, 2006, 103 (4), pp.753-780. 10.3406/bspf.2006.13504 . hal-02172669

\section{HAL Id: hal-02172669 \\ https://hal.science/hal-02172669}

Submitted on 4 Jul 2019

HAL is a multi-disciplinary open access archive for the deposit and dissemination of scientific research documents, whether they are published or not. The documents may come from teaching and research institutions in France or abroad, or from public or private research centers.
L'archive ouverte pluridisciplinaire HAL, est destinée au dépôt et à la diffusion de documents scientifiques de niveau recherche, publiés ou non, émanant des établissements d'enseignement et de recherche français ou étrangers, des laboratoires publics ou privés.

\section{()ㅜㅇㅜ}

Distributed under a Creative Commons Attribution - NoDerivatives| 4.0 International 


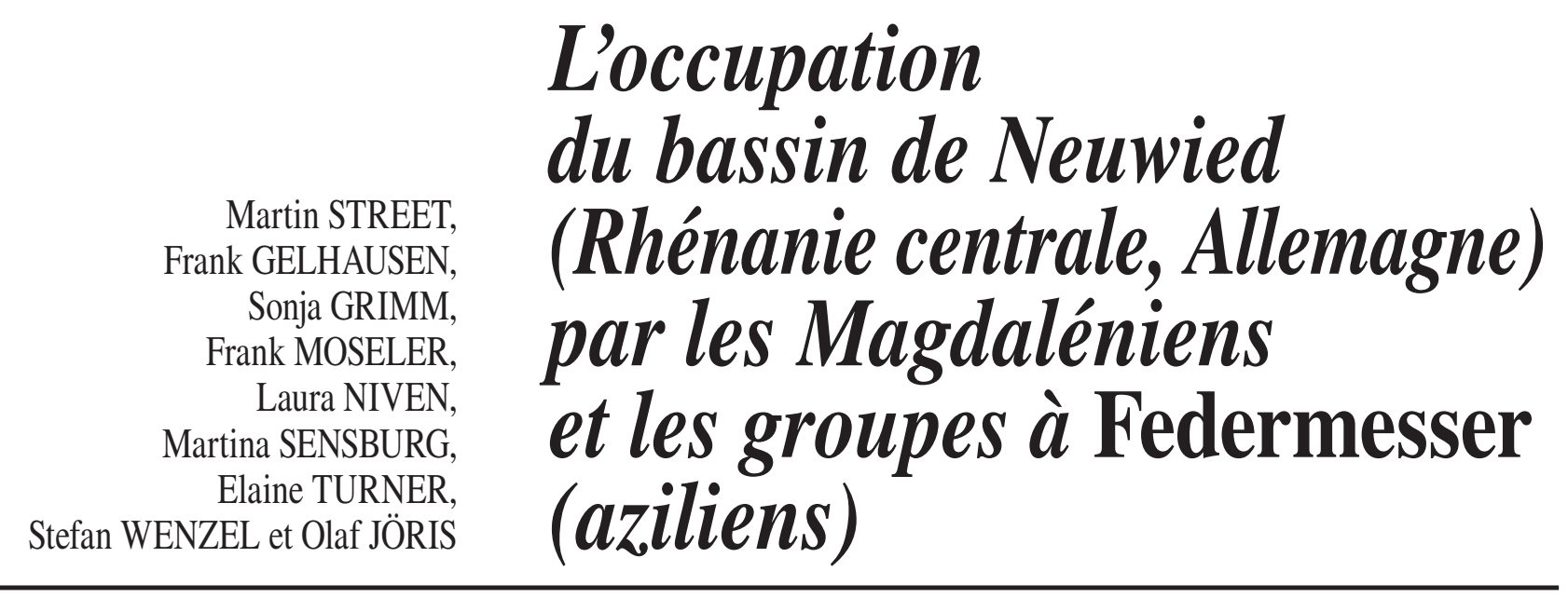

\begin{abstract}
Résumé
Depuis les travaux pionniers d'Hermann Schaaffhausen en 1883 au Martinsberg à Andernach, et grâce au recouvrement de la région à la fin de l'Allerød par des amas de cendres déposées au cours de l'éruption du Laacher See, la Rhénanie centrale est connue comme une région prometteuse pour l'abondance des sites tardiglaciaires et pour leur qualité de préservation. Aujourd'hui, plus de 120 ans après les premières fouilles de Schaaffhausen, deux grands sites magdaléniens - Andernach et Gönnersdorf-ainsi que six gisements des groupes à Federmesser ont été découverts dans cette région. Les sites à Federmesser se trouvent à Andernach (horizon supérieur), à Boppard, à Niederbieber (le plus vaste d'entre tous), à Kettig et à Urbar, cinq gisements dont l'occupation précède l'éruption du Laacher See, ainsi qu'à Bad Breisig, occupé après l'éruption. En outre, plusieurs découvertes de foyers isolés informent sur des activités humaines qui se sont déroulées dans les paysages de l'Allerød, à l'écart des plus grands campements. Les données archéologiques apportent des informations précises à la fois sur l'environnement et sur le mode de vie ainsi que sur la culture matérielle des Magdaléniens et des groupes à Federmesser en Rhénanie centrale. D'un moment à l'autre, en parallèle des changements environnementaux et de leurs conséquences en termes de ressources disponibles, on observe des transformations radicales dans le domaine des techniques, dans l'organisation des campements et dans les manifestations artistiques. Par contraste avec ces sociétés bien étudiées (le Magdalénien des steppes loessiques et les groupes à Federmesser des milieux boisés de l'interstade), les «cultures» intermédiaires sont mal connues. Les seules évidences pour cette transition proviennent du secteur sud-ouest de Gönnersdorf, des inhumations de Bonn-Oberkassel ainsi que de NeuwiedIrlich.
\end{abstract}

\title{
Abstract
}

Since the pioneering work of Hermann Schaaffhausen in 1883 on the Martinsberg at Andernach and due to the protection of the area by the eruptive masses of the late Allerød Laacher See volcano, the German Central Rhineland has been known to be a promising region for the preservation and discovery of Late Glacial sites. Today, more than 120 years after 
Schaaffhausen's initial excavation, two large Magdalenian sites - Andernach and Gönnersdorf - as well as six Federmesser sites are known from the Central Rhineland. The latter are Andernach (upper find horizon), Boppard, Niederbieber (the most extensive of these sites), Kettig and Urbar, all of which pre-date the Laacher See eruption, and Bad Breisig, post-dating this event. Furthermore, repeated discoveries of isolated hearths show human activities in the Allerod landscape away from the larger encampments. The archaeological record provides detailed insight into both the environment and life of the Central Rhineland Magdalenian and Federmesser groups and their material culture. The changes in environment and available subsistence resources between the Magdalenian and Federmesser groups were accompanied by radical shifts in material technology, the internal spatial organisation of settlements and the manifestation of artistic expression. By contrast with these well-defined groups, the "cultures" intermediate between the Magdalenian hunter-gatherers of the open loess steppe and the Federmesser groups of the interstadial woodlands are scarcely known. The only evidence for this interval comes from the southwestern part of the Gönnersdorf site and from the burials at Bonn-Oberkassel and Neuwied-Irlich.

\section{INTRODUCTION}

Depuis plusieurs années, le centre des Recherches paléolithiques du Römisch-Germanisches Zentralmuseum de Mayence conduit des recherches sur des sites d'habitat tardiglaciaires de Rhénanie centrale en Allemagne (fig. 1). Ce sont en particulier les sites du bassin de Neuwied, qui sont exceptionnellement bien conservés grâce aux dépôts de téphras de l'éruption du Laacher See datant de 13000 cal. BP.
Les sites sont attribués à deux traditions, au Magdalénien du Paléolithique supérieur final et à celle des groupes à Federmesser du Paléolithique final. La première tradition n'est représentée que sur deux sites, les deux occupations très importantes de Gönnersdorf et d'Andernach-Martinsberg, tandis que les sites à Federmesser sont plus éphémères, mais aussi plus nombreux. Les restes humains de Neuwied-Irlich et Bonn-Oberkassel ont un âge intermédiaire entre le Magdalénien et les groupes à Federmesser.

L'histoire de la recherche archéologique sur le Tardiglaciaire de Rhénanie centrale remonte au début

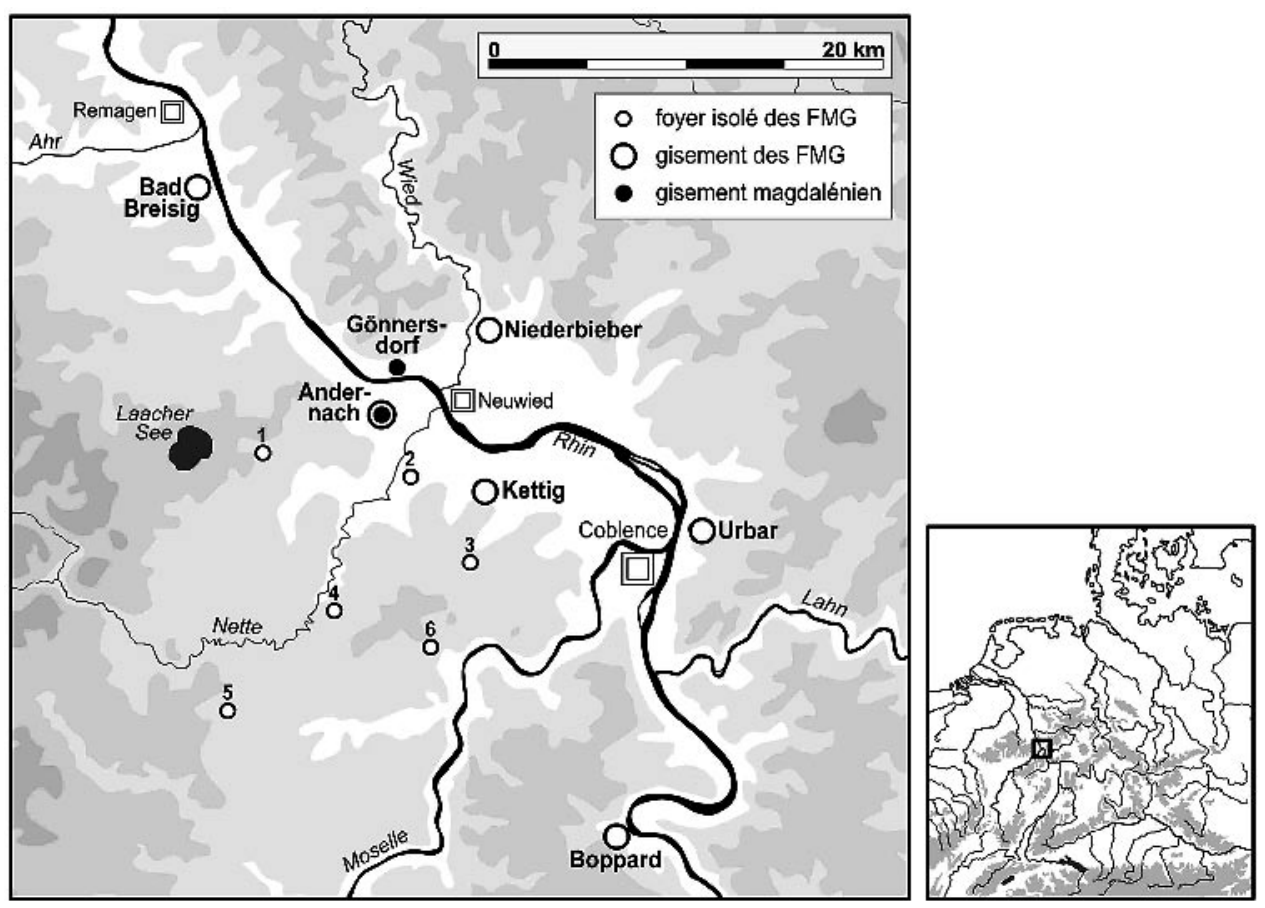

Fig. 1 - Cartes des sites mentionnés dans le texte (NB : FMG : groupes à Federmesser). Des foyers isolés ont été découverts à Nickenich (1), à Miesenheim 3 (2), à Bassenheim (3), à Ochtendung (4), à Polch (5) et à Kobern (6). 
des années 1880, quand Hermann Schaaffhausen, anatomiste et antiquaire de Bonn, prit l'initiative de rechercher des preuves d'existence de «l'homme diluvien » antérieures à l'éruption très importante du Laacher See, dont on pensait à l'époque qu'elle avait eu lieu autour de la transition Pléistocène-Holocène. En 1883, Schaaffhausen fouilla à AndernachMartinsberg un site magdalénien recouvert par plusieurs mètres de pierre ponce provenant de l'éruption du Laacher See (Schaaffhausen, 1888). À partir de ce moment-là, la Rhénanie centrale apparut comme une région prometteuse pour la conservation et la découverte de sites tardiglaciaires. Cette impression se confirma au début du $20^{\mathrm{e}}$ siècle avec la découverte de restes humains juste au-dessous des pierres ponces du Laacher See à Weissenthurm et à Plaidt-Rauschermühle (Hörter, 1928), ainsi que dans les années 1960 avec la fouille restreinte d'un site à Federmesser à Urbar, près de Coblence (Eiden et Löhr, 1974; Baales et al., 1998).

En 1968, la découverte d'un second site magdalénien à Gönnersdorf, Neuwied (Bosinski, 1970) a suggéré que ce nouveau gisement pouvait, tout comme celui d'Andernach-Martinsberg, faire partie d'un système d'occupation complexe au cours du Magdalénien récent. Ceci motiva une nouvelle analyse des assemblages lithiques et fauniques d'Andernach (Bosinski et Hahn, 1972; Poplin, 1972) et donna une nouvelle motivation aux efforts pour tenter de localiser l'emplacement du site d'Andernach-Martinsberg, lequel fut finalement redécouvert par hasard en 1979 (Veil, 1978 et 1979). La fouille programmée du Martinsberg entre 1981 et 1983 confirma non seulement l'existence de l'horizon magdalénien, mais révéla aussi un second horizon attribué aux groupes à Federmesser (Veil, 1982a).

En 1980, juste avant les nouvelles recherches à Andernach, un nouveau site majeur des groupes à Federmesser fut découvert à Neuwied-Niederbieber (Bosinski et al., 1982). Une période d'intensification des recherches dans la région fut récompensée par la reconnaissance de plusieurs autres sites de cette même période : Kettig dans le bassin de Neuwied (Baales, 2002) ainsi que Bad Breisig et Boppard, situés respectivement au nord et au sud (Baales et Jöris, 2001 et 2002; Baales et al., 2001; Grimm, 2003 et 2004; Wenzel, 2004; Wenzel et Álvarez Fernández, 2004) (fig. 1).

\section{Les sites magdaléniens}

Les sites de Gönnersdorf et d'AndernachMartinsberg, éloignés par $2 \mathrm{~km}$ l'un de l'autre, se trouvent respectivement sur la rive nord et sud du Rhin, lequel coule à cet endroit vers l'ouest. Les deux sites sont proches de l'endroit où le fleuve quitte le bassin ouvert de Neuwied par la «porte d'Andernach» pour retourner dans une gorge étroite.

Gönnersdorf est situé à l'extrémité ouest d'un promontoire formé par une moyenne terrasse du Rhin. Andernach-Martinsberg se trouve sur une pente formée par une coulée de lave du Pléistocène moyen, en visà-vis du site de Gönnersdorf.

À Gönnersdorf, $687 \mathrm{~m}^{2}$ au total ont été fouillés entre 1968 et 1976 (Bosinski, 1979). Quatre concentrations de vestiges étendues et distinctes (concentrations I à IV), caractérisées par divers agencements de grandes dalles de pierre, par des groupements de fosses, par du matériel lithique et faunique et par des épandages d'ocre, ont été interprétées dès la fouille comme des structures d'habitat (fig. 2). Des analyses ultérieures ont démontré que la concentration II pouvait être subdivisée en une zone centrale (concentration IIa) et une zone immédiatement au nord-ouest, la concentration IIb (Eickhoff, 1988). Il est également devenu clair qu'une zone située au sud-ouest du site et plus pauvre en vestiges (concentration SW) représentait une unité distincte (Buschkämper, 1993).

La zone du Martinsberg, qui a été fouillée entre 1981 et 1983, fut appelée Andernach 2 (AN2) (fig. 3). L'horizon magdalénien y a livré trois concentrations de matériel lithique et faunique, distinctes mais plus ou moins tronquées : les concentrations I, II et III (Veil, 1982b et 1984; Eickhoff, 1992; Floss et Teberger, 2002; Street, 1993) On a pu démontrer que cette nouvelle zone est contiguë à celle qui fut fouillée par Schaaffhausen (Bolus et Street, 1985). Entre 1994 et 1996, de nouvelles fouilles sur le Martinsberg (Andernach 3, AN3) ont mis au jour une nouvelle concentration de matériel magdalénien (concentration IV) à environ 15 mètres au sud des fouilles d'Andernach 2 (Bergmann, 1999; Holzkämper, 1999; Bergmann et Holzkämper, 2002). Tandis que les concentrations I, III et IV d'Andernach sont caractérisées par des zones dallées et des complexes de fosses, et apparaissent donc comme des structures d'habitat similaires à celles de Gönnersdorf I, II et III, la concentration II semble correspondre à une zone restreinte dévolue au travail du silex et peut-être à celui de l'ivoire.

\section{Les sites des groupes à Federmesser}

Les fouilles conduites entre 1981 et 1983 à Andernach-Martinsberg (AN2) (Veil, 1982a) ont également mis au jour une occupation attribuée aux groupes à Federmesser qui fut référencée «AN2-FMG» (fig. 3). Cette occupation, qui recouvre directement l'horizon magdalénien, se situe entre les trois occupations plus anciennes et les chevauche partiellement. La fouille de 1994 à 1996 (AN3) a confirmé l'existence au sud d'une seconde aire dense en vestiges appartenant aux groupes à Federmesser (AN3-FMG) (Kegler, 1999 et 2002), déjà identifiée par un sondage limité des années 1980.

Le site à Federmesser de Niederbieber est situé au nord-est du Rhin sur un promontoire de la vallée de la Wied, un affluent du Rhin. Les fouilles successives d'une zone de plusieurs milliers de $\mathrm{m}^{2}$ ont porté le nombre total de concentrations de matériel lithique et parfois faunique à plus de 17, certaines étant subdivisées en unités plus petites (fig. 4). L'analyse a commencé à travers plusieurs mémoires de maîtrise 
portant sur des concentrations spécifiques (NiBi I, II, IV-VII : Loftus, 1984 et 1985 ; Winter, 1986; Husmann, 1988 et 1989; Thomas, 1990; Freericks, 1989 et 1991). Elle a également donné lieu à des synthèses réalisées par M. Bolus (1992) et M. Baales (2003). L'analyse spatiale se poursuit avec la participation de nouveaux chercheurs et l'application de nouvelles méthodes d'analyse (Gelhausen et al., 2004).

Le site du Paléolithique final découvert à Kettig se situe sur la terrasse inférieure occidentale du Rhin, au bord d'un paléochenal du fleuve. Une zone de $240 \mathrm{~m}^{2}$ y a été fouillée en 1993 (Baales, 2002).

Le gisement d'Urbar se situe à l'est du Rhin sur une terrasse surplombant d'environ 80 mètres le fleuve actuel. Une très petite portion du site, en partie détruit, a pu être fouillée et seule une surface de $15 \mathrm{~m}^{2}$ a pu être explorée lors de brèves campagnes dans les années 1960, 1970 et 1980 (Baales et al., 1998).

Bad Breisig est situé au nord-ouest du bassin de Neuwied, sur la terrasse inférieure occidentale du

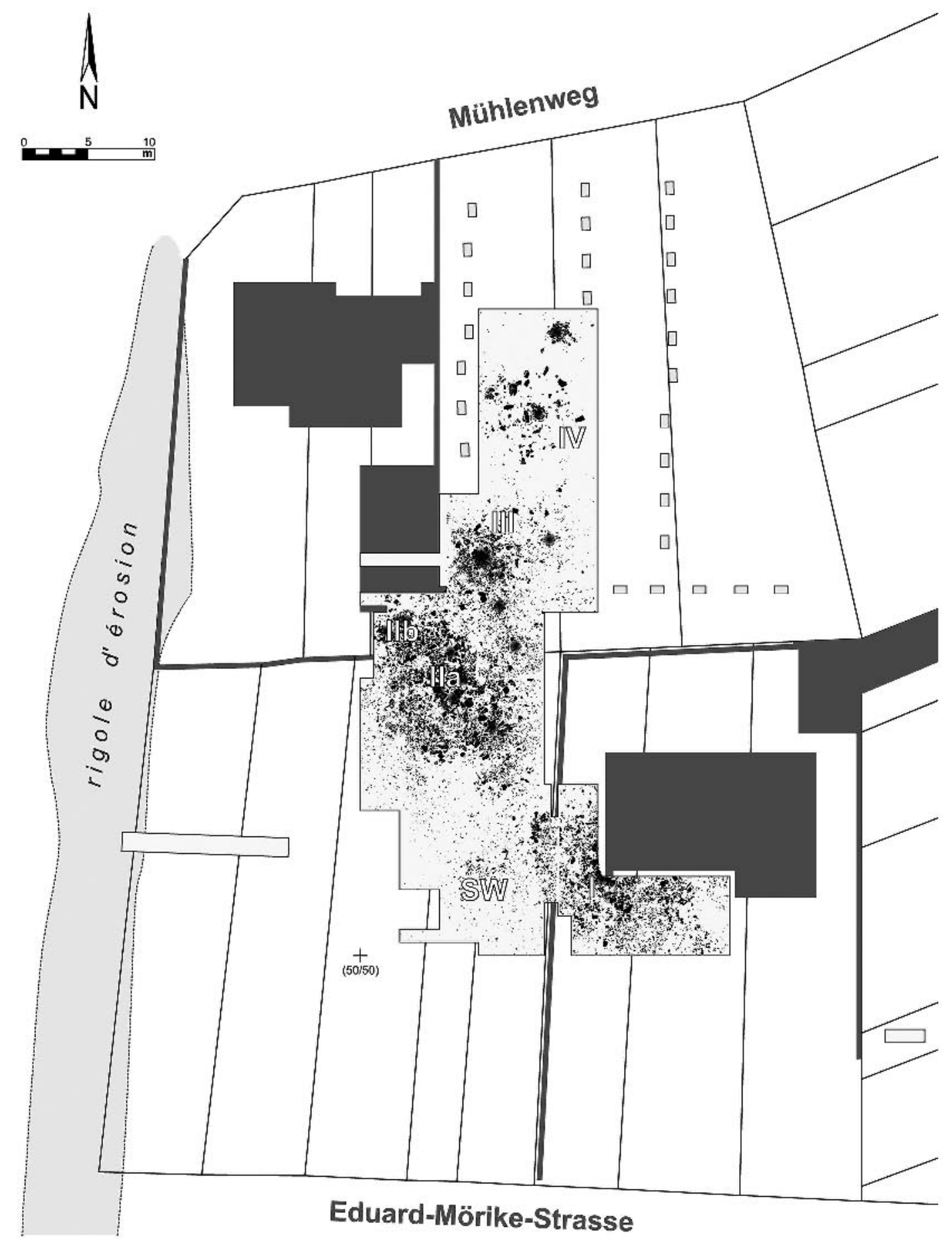

Fig. 2 - Plan des fouilles de Gönnersdorf montrant l'étendue des fouilles par rapport aux constructions modernes. On voit l'emplacement des structures d'habitat magdaléniennes (concentrations I-IV) et du secteur sud-ouest (Gönnersdorf SW). Les éléments représentés dans la zone fouillée correspondent à des blocs et des dalles de pierre utilisés pour la construction des habitations ainsi qu'à d'autres manuports aux fonctions différentes. Les cercles gris indiquent l'emplacement des foyers. 


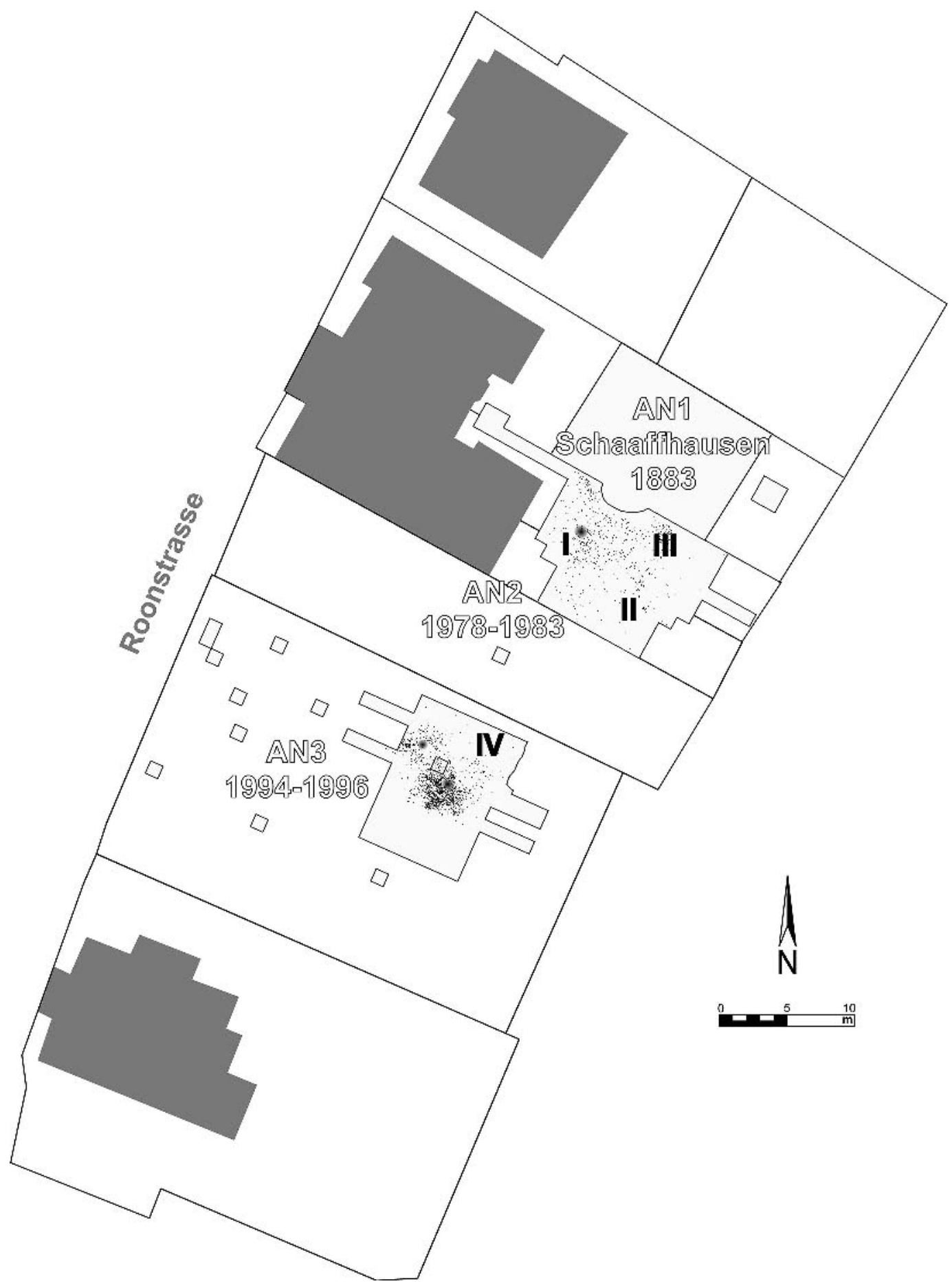

Fig. 3 - Plan d'Andernach-Martinsberg montrant l'étendue des différentes campagnes de fouille (Schaaffhausen, Andernach 2, Andernach 3) par rapport aux constructions modernes (d'après Kegler, 2002, avec modifications). Les chiffres (I-IV) indiquent la position des concentrations magdaléniennes identifiées par de grands éléments de construction et par des fosses (non figurées ici). Sur ce plan, les accumulations de points noirs correspondent à des artefacts lithiques appartenant à l'occupation plus récente attribuée aux groupes à Federmesser. Les cercles gris indiquent l'emplacement des foyers de cette occupation la plus récente.

Rhin. Au moins la moitié du site a été détruite avant sa découverte par l'exploitation d'une carrière, mais il a été possible d'en fouiller environ $50 \mathrm{~m}^{2}$ (Baales et Jöris, 2001 et 2002; Baales et al., 2001; Grimm, 2003 et 2004). Ce site est unique dans la région parce qu'il repose au-dessus des cendres du Laacher See, déposées à la fin de l'Allerød. Cette occupation des groupes à Federmesser est donc légèrement plus récente que celles du bassin de Neuwied, mais elle est encore associée à une faune au caractère interstadiaire. La présence à Bad Breisig de pointes à retouche basale semblables aux pointes de Malaurie est cohérente avec l'âge du site (Grimm, 2003 et 2004). 

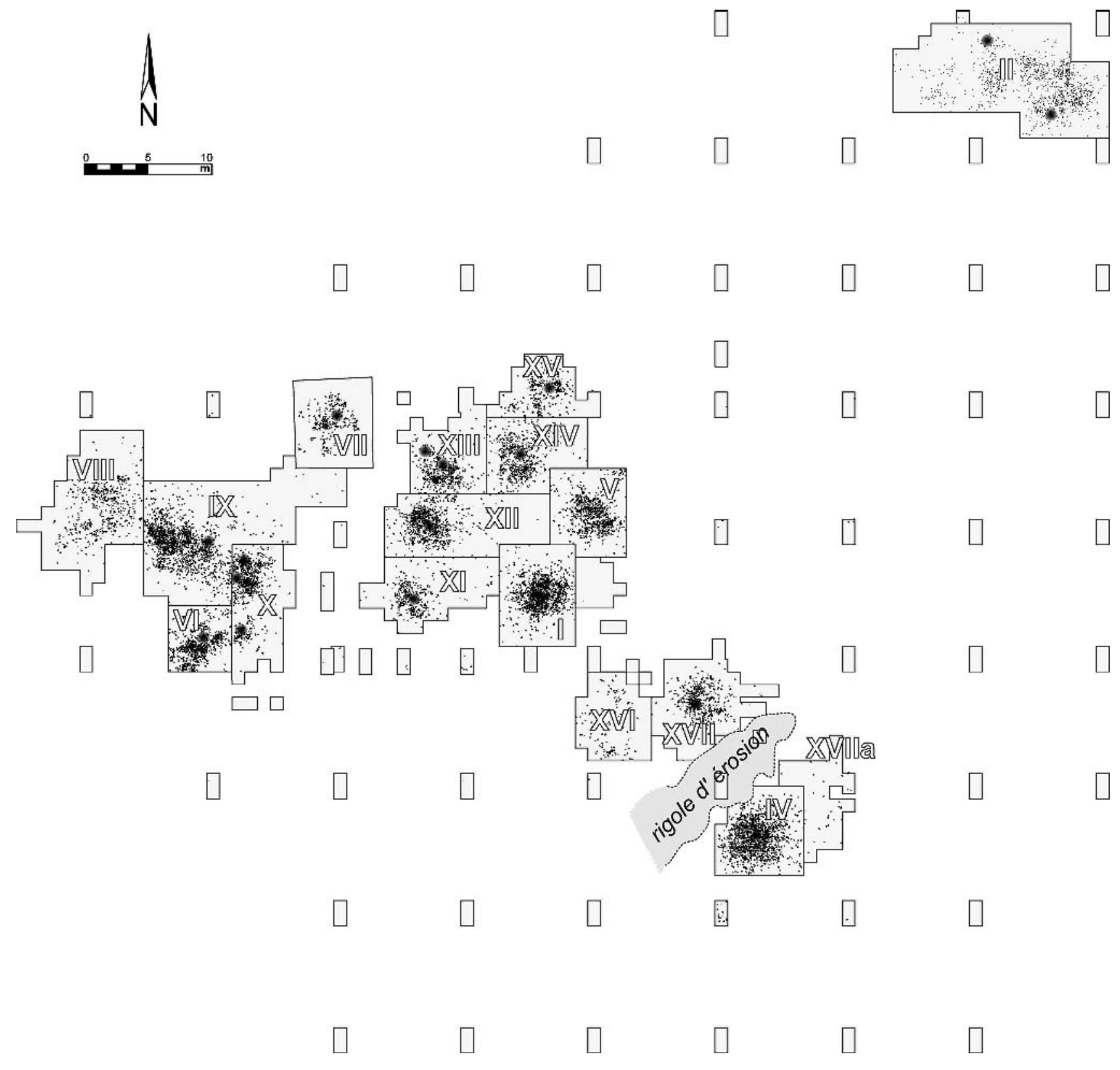

Fig. 4 - Plan de Niederbieber montrant l'emplacement des différentes campagnes de fouille (I-XVIIa). Les points correspondent à des artefacts lithiques attribués aux groupes à Federmesser. Les foyers figurent en gris.

La plus récente découverte a eu lieu à $25 \mathrm{~km}$ au sud du bassin de Neuwied : c'est celle du site à Federmesser de Boppard, qui devait se trouver immédiatement au bord du Rhin pendant le Tardiglaciaire.

\section{LE CONTEXTE CHRONOLOGIQUE ET CLIMATOLOGIQUE}

En Rhénanie centrale, comme ailleurs en Europe, la transition entre Paléolithique supérieur et Paléolithique final a lieu à un moment où se produisent des changements environnementaux considérables qui aboutissent à la disparition de la steppe pléistocène et au début du reboisement (fig. 5).
Les datations ${ }^{14} \mathrm{C}$ (Housley et al., 1997) placent les occupations magdaléniennes de Gönnersdorf et d'Andernach-Martinsberg aux alentours de 13000 BP (environ 15500 cal. BP), vers la fin d'une phase froide et très sèche (Greenland Stadial $2 a$ : GS-2a) et immédiatement avant l'interstade tardiglaciaire (GI-1).

Les sites attribués aux groupes à Federmesser appartiennent à la dernière partie de l'interstade tardiglaciaire (de GI-1c à GI-1a), auquel on peut assimiler les zones polliniques traditionnelles Bølling (stricto sensu) et Allerød. La faune associée indique régulièrement des conditions de forêt tempérée (fig. 5). Quant aux dates radiocarbone, elles s'inscrivent entre 11800 et $10800 \mathrm{BP}$. 


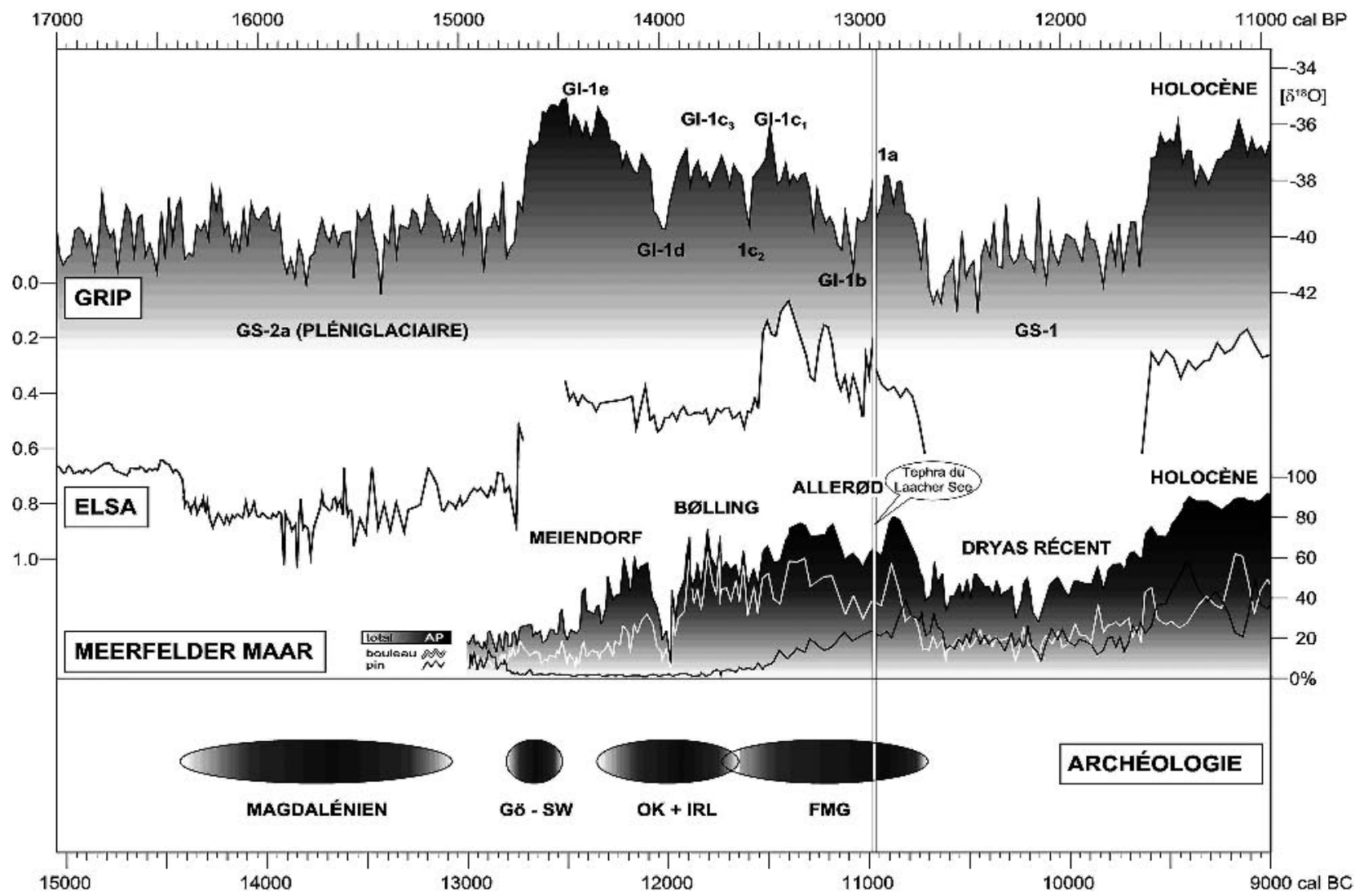

Fig. 5 - Changements climatiques et environnementaux pendant le Tardiglaciaire reconstitués à partir de différentes sources. En haut : données climatiques sur la transition Tardiglaciaire-Holocène d'après les variations du taux $\delta^{18} \mathrm{O}$ dans le forage GRIP (d'après Johnsen et al., 2001, avec modifications; le début de l'Holocène est fixé à 9640 cal. BC en suivant Friedrich et al., 2005, et la durée du Dryas récent est établie d'après Baales et al. 2002). Au centre : la courbe ELSA (Eifel Laminated Sediment Archive) (d'après Sirocko et al., 2005, avec modifications et corrélations avec la chronologie GRIP) montre la production organique enregistrée dans les sédiments de remplissage des maars volcaniques de l'Eifel ouest. En dessous : séquence pollinique (courbes pour le bouleau, le pin et pour l'ensemble des pollens arboréens) reconstituée à partir des varves du Meerfelder Maar (Eifel ouest) et montrant la traduction régionale des interstades Meiendorf, Bølling et Allerød et le commencement brutal du Dryas récent (d'après Litt et Stebich, 1999, modifié en suivant Street et al., 2002, fig. 4). En bas : séries de dates calibrées pour les différents technocomplexes du Tardiglaciaire reconnus en Rhénanie centrale. GÖ-SW : Gönnersdorf, secteur sud-ouest; OK : Bonn-Oberkassel; IRL : Neuwied-Irlich; FGM : groupes à Federmesser. Diagramme construit à l'aide du logiciel de calibration "CalPal” (Weninger et Jöris, 2004; www.calpal.de). NB : Échelle de temps supérieure : cal. BP; échelle de temps inférieure : cal. BC.

L'environnement boisé de l'Allerød fréquenté par les groupes à Federmesser présentait une biomasse animale inférieure à celle de la steppe à mammouths habitée par les groupes magdaléniens. On ne trouvait plus durant l'Allerød ces grands troupeaux d'animaux sociaux (chevaux, rennes, bisons...) qui pouvaient être exploités efficacement par de larges groupes humains agissant en coopération. Avec les rassemblements de rennes à l'automne, c'est un surplus saisonnier assurément disponible, et peut-être d'importance critique, qui avait disparu. Cette transformation des paysages ouverts de prairie en biotopes boisés et ces changements dans les ressources disponibles se sont accompagnés de mutations radicales que nous décrirons plus loin concernant la culture matérielle paléolithique, l'organisation spatiale interne des campements et les expressions artistiques.

Aucune occupation n'est connue en Rhénanie centrale pour la transition entre ces deux phases bien définies, mais les datations ${ }^{14} \mathrm{C}$ sur les restes humains et la faune associée de Bonn-Oberkassel (Baales et Street, 1998) ainsi que sur les restes humains de
Neuwied-Irlich (Baales, 2002) se placent entre celles du Magdalénien de Rhénanie centrale et celles des groupes à Federmesser, c'est-à-dire autour de 12000 BP (fig. 5).

\section{ÉCOLOGIE ET SUBSISTANCE}

\section{La faune du Magdalénien}

La faune magdalénienne du bassin de Neuwied contient de nombreux représentants du cortège classique définissant la «steppe à mammouths » (Guthrie, 1982). Cette généralité vaut pour Gönnersdorf comme pour Andernach-Martinsberg, mais il existe des nuances dans le détail de la composition faunique des diverses concentrations de matériel retrouvées dans les deux sites (tabl. 1).

En termes de rendement en viande et de valeur calorique, l'espèce comestible la plus importante dans les deux sites et dans tous les secteurs est le cheval. Les autres espèces jouent un rôle bien moins significatif et 


\begin{tabular}{|c|c|c|c|c|c|c|c|c|c|c|c|c|c|c|c|c|c|c|c|c|}
\hline 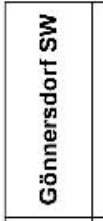 & 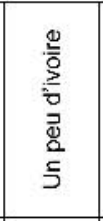 & 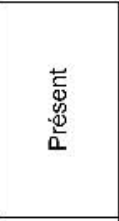 & 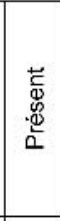 & & 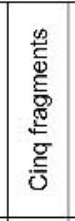 & & & & & & & & & & & & & 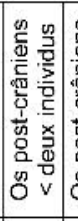 & 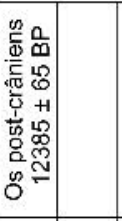 & \\
\hline 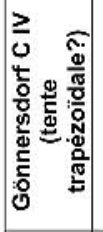 & & 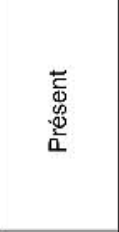 & 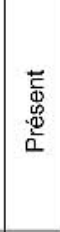 & & & & & & & & & & & & & 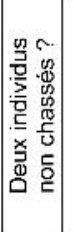 & & & & \\
\hline 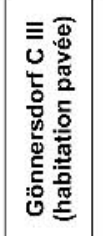 & 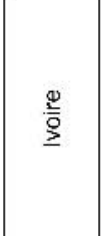 & 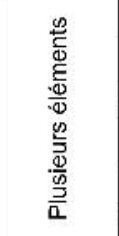 & 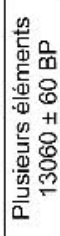 & & 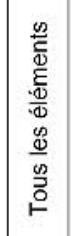 & 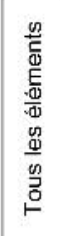 & 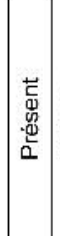 & 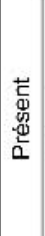 & 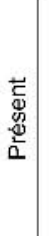 & 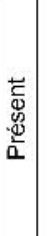 & & & & & 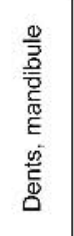 & 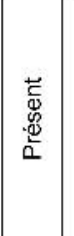 & 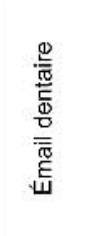 & & & \\
\hline 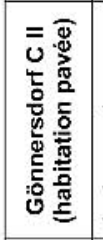 & 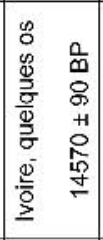 & 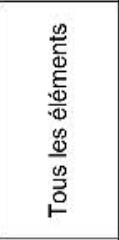 & 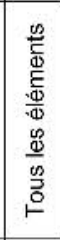 & & 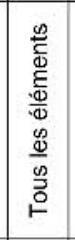 & 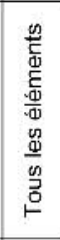 & 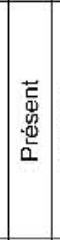 & 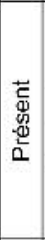 & 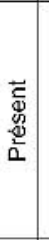 & 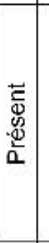 & & & & 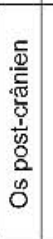 & 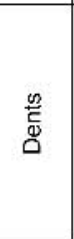 & 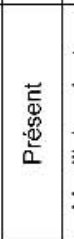 & 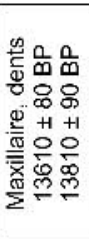 & 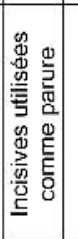 & & \\
\hline 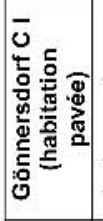 & 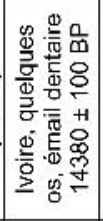 & 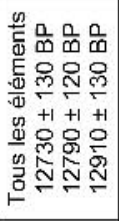 & 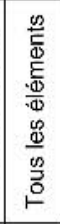 & 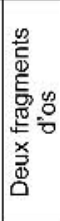 & 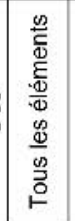 & 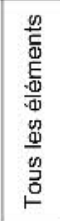 & 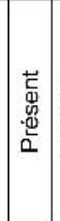 & 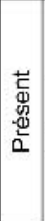 & 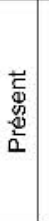 & 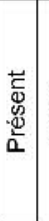 & $\begin{array}{l}\stackrel{8}{8} \\
5 \\
5\end{array}$ & $\begin{array}{l}\text { g } \\
0 \\
5 \\
5\end{array}$ & 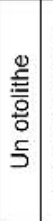 & 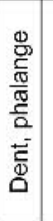 & & 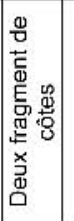 & & 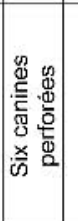 & & \\
\hline 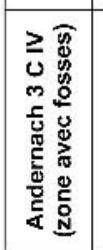 & $\begin{array}{l}\underline{\underline{\underline{0}}} \\
\underline{2}\end{array}$ & 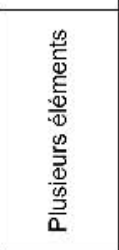 & 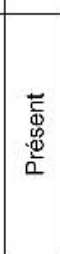 & & 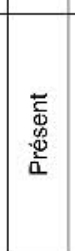 & 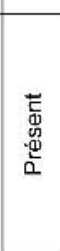 & & 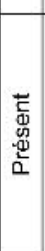 & & & & & & & & & & & & \\
\hline 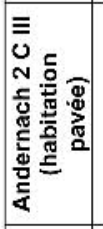 & $\stackrel{0}{\underline{0}}$ & 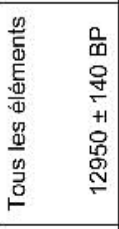 & 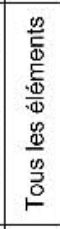 & & 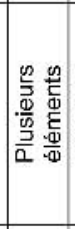 & 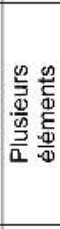 & & $\begin{array}{l}\text { g } \\
\text { I } \\
\text { ᄃ }\end{array}$ & 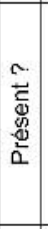 & 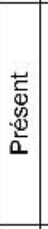 & & & & & & 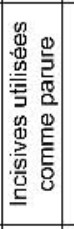 & & & 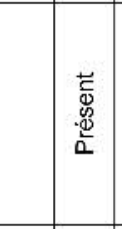 & \\
\hline 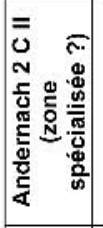 & $\stackrel{0}{2}$ & 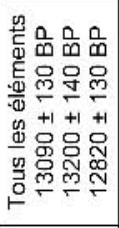 & 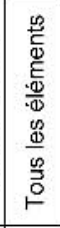 & & 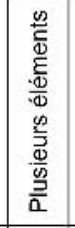 & 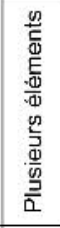 & 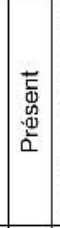 & 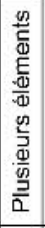 & & & & & & & & & & & 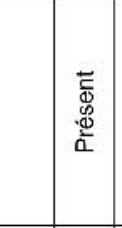 & $\begin{array}{l}80 \\
5 \\
5\end{array}$ \\
\hline 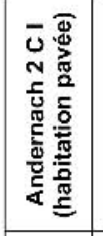 & $\begin{array}{l}\stackrel{\underline{\nu}}{\overline{0}} \\
\underline{2}\end{array}$ & 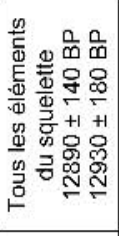 & 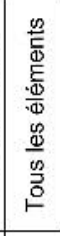 & & 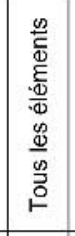 & 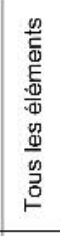 & & $\begin{array}{l}\text { : } \\
\stackrel{2}{5}\end{array}$ & 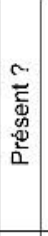 & 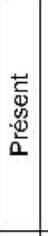 & & & & & & & & 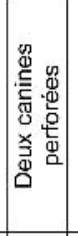 & 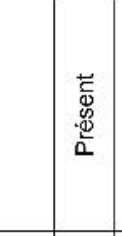 & \\
\hline 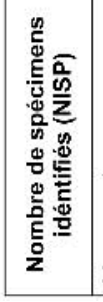 & 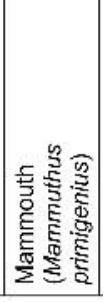 & 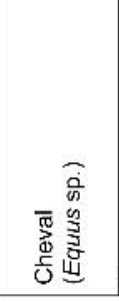 & 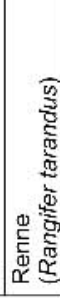 & 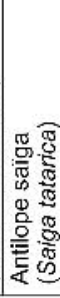 & 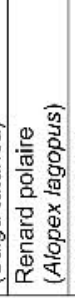 & 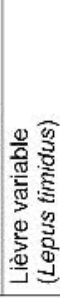 & \begin{tabular}{|c|}
$x$ \\
0 \\
0 \\
0 \\
0 \\
0 \\
0 \\
0 \\
0 \\
0 \\
0 \\
0 \\
0 \\
0 \\
0
\end{tabular} & 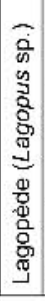 & 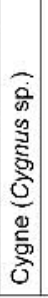 & 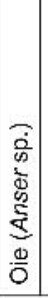 & 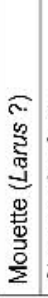 & 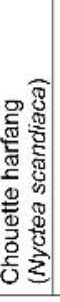 & 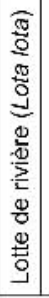 & 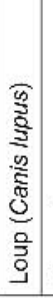 & 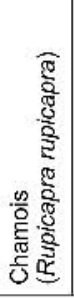 & 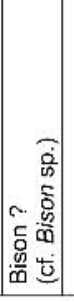 & 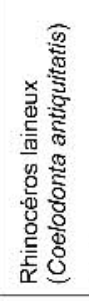 & 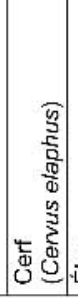 & 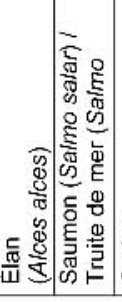 & 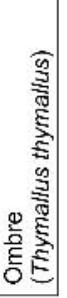 \\
\hline
\end{tabular}


nombre d'entre elles ont pu être chassées ou piégées pour d'autres raisons qu'alimentaires (fourrures, plumes, etc.).

\section{La faune de Gönnersdorf}

L'analyse de la faune de Gönnersdorf n'étant pas encore achevée, seules des données provisoires peuvent être évoquées. Cependant, il semble déjà que, dans le cas du cheval, le nombre de vestiges identifiés et le nombre minimum d'individus estimés semblent être, dans une certaine mesure, proportionnels à la dimension du secteur étudié.

La faune de la concentration I de Gönnersdorf a été décrite en détail par F. Poplin (1976). La première campagne de fouille a livré les restes de 13 chevaux au moins, représentés par environ 500 ossements et dents. Les restes de renards polaires sont beaucoup plus nombreux (environ 1400) et ils proviennent de 30 animaux au moins. Récemment, les nouvelles analyses sur le matériel faunique de Gönnersdorf ont modifié quelques-unes de ces données. À présent, environ 700 restes post-crâniens et environ 300 restes crâniens et dentaires de la concentration I sont attribués au cheval. Le nombre d'ossements et de dents de renard polaire atteint maintenant 2500 environ. Pourtant, le nombre minimum d'individus identifiés reste presque identique à celui qui fut déterminé par F. Poplin. Le renard polaire est bien moins fréquent dans les autres concentrations, et la concentration I totalise plus de $90 \%$ du matériel.

Les autres espèces reconnues par F. Poplin dans la concentration I de Gönnersdorf comprennent le mammouth, le renne, le bison, l'antilope saïga, le cerf, le lièvre variable, le loup ainsi que des oiseaux (corbeau, lagopède, cygne, oie, chouette des neiges, mouette) et des poissons (truite, lotte de rivière ainsi qu'un cyprinidé). Le rôle et l'importance de ces espèces sont extrêmement variables.

Le mammouth est surtout représenté par de l'ivoire, sous forme d'artefacts, de restes de débitage et surtout de petits fragments. On trouve aussi un petit nombre d'ossements et de molaires. Le débat à propos de l'état subfossile possible d'un fémur complet (Poplin, 1976, p. 50) a pu être tranché grâce à une datation directe qui prouve que cet ossement provenait effectivement d'un animal décédé longtemps avant l'occupation magdalénienne. Le renne est représenté par environ 180 ossements et dents provenant d'au moins quatre animaux chassés et par environ 90 morceaux de bois, dans certains cas manifestement apportés sur le site comme bois de chute. Le bison est représenté par deux fragments de côtes et F. Poplin considère qu'ils pourraient avoir été utilisés comme outils pour creuser. L'antilope saïga est identifiée sur la base de deux fragments de métatarse; aucun autre spécimen n'a été retrouvé par la suite et le rôle de cette espèce sur le site n'est pas clair. Le cerf n'est représenté que par un groupe de six canines perforées. Cette pièce de parure n'a rien à voir avec la subsistance et elle a pu avoir été importée depuis une distance lointaine. Le lièvre variable a été clairement chassé ou piégé et tous les éléments du squelette de plusieurs individus ont été retrouvés. Le loup est représenté dans la concentration I par des fragments de dent et par une seule phalange. Il est possible que ces vestiges correspondent à des peaux auxquelles têtes et pattes étaient encore attachées. Les oiseaux retrouvés pourraient correspondre à de nombreuses utilisations, depuis la subsistance jusqu'à l'ornementation (plumes, griffes).

Gönnersdorf II a livré le plus grand nombre de restes fauniques. Dans le cas du cheval, cela représente environ 2100 exemplaires post-crâniens et à peu près 850 fragments crâniens et dentaires. Sur la base des ossements du pied, au moins 28 animaux sont représentés. Cent quatre-vingt-huit pièces de la concentration II sont identifiées comme renard polaire, représentant $6,77 \%$ de la totalité des restes totaux de ce taxon, ceci démontrant clairement que l'espèce était moins importante ici que dans la concentration I. D'après la dentition, on peut estimer à quatre, pas plus, le nombre de renards. Dans cette concentration II, le lièvre dépasse le renard polaire en importance et plus de 400 restes provenant de plusieurs individus ont été retrouvés.

La gamme des espèces retrouvées dans la concentration II diffère donc légèrement de celle de la concentration I (tabl. 1). Néanmoins, les espèces les plus importantes restent les mêmes, la différence ne provenant que des taxons qui ne sont représentés que par une très petite quantité de vestiges. Le renne est représenté ici encore autant par les ossements postcrâniens (animaux chassés) que par les bois, alors que le cerf n'est attesté que par quelques fragments d'incisives transformées en parure. Â la différence de la concentration I, le loup est ici représenté par une série d'ossements post-crâniens, mais pas par des dents. Un grand bovidé (bison?) est ici attesté par un petit nombre d'ossements du membre antérieur. Le chamois est présent sous forme de quelques fragments de dent et de mandibule. Le rhinocéros laineux est présent, mais les fragments de maxillaire et de dents datés directement démontrent que ce matériel a été collecté simplement à l'état subfossile. Les quatre espèces d'oiseaux les plus importantes inventoriées dans la concentration I existent aussi dans la concentration II.

La concentration III comporte à peu près le même spectre faunique que la concentration II mais avec moins de matériel, en général. Le cheval y est représenté par environ 300 restes provenant d'au moins sept individus, d'après l'analyse des ossements du pied. Dans cette même concentration III, 71 vestiges sont attribués au renard polaire, représentant seulement $2,55 \%$ des restes totaux de cette espèce, et il n'a pas été possible de reconnaître plus d'un individu. Comme dans la concentration II, les restes de lièvres sont plus nombreux avec environ 100 spécimens. Le renne est représenté par les ossements post-crâniens d'au moins deux animaux chassés et par des bois. Quatre espèces d'oiseaux sont toujours représentées, mais le loup est absent. Dans les deux concentrations II et III, la présence d'ossements du grand bovidé, de fragments de dents de rhinocéros et de dents de chamois pourrait 
suggérer que ces concentrations entretenaient des liens.

Les restes fauniques sont très peu présents dans la concentration IV. Seuls deux chevaux peuvent être mis en évidence à travers les quelque 20 restes identifiés. Aucun reste découvert dans cette partie du site n'a pu être attribué au renard polaire, au renne ou au lièvre, ces espèces habituellement présentes par ailleurs. Ceci distingue cette zone des autres secteurs précédemment décrits. À part le cheval, la seule espèce identifiée est un grand bovidé représenté par quatre ossements postcrâniens retrouvés en position stratigraphique bien plus élevée que les autres vestiges. Ils proviennent d'un adulte et d'un animal juvénile et ils ont été rongés par un carnivore. On peut donc probablement les considérer comme sans rapport avec le contexte archéologique.

Dans la zone au sud-ouest du site, au moins cinq chevaux sont représentés par 150 restes. Seuls cinq restes de renards ont été découverts dans cette zone et il est possible qu'ils aient simplement glissé depuis la périphérie de la concentration I. Le renne n'est représenté que par une petite quantité de matériel et le lièvre est absent. Les seuls vestiges de mammouth consistent en trois fragments d'ivoire, et il n'y a pas d'oiseau. En revanche, deux espèces de cervidés, le cerf et l'élan, sont représentées ici par des ossements post-crâniens, ce qui n'est pas le cas dans les concentrations principales. La datation directe au ${ }^{14} \mathrm{C}$ d'un radius d'élan a fourni un âge beaucoup plus jeune que ceux obtenus sur les ossements de chevaux et de rennes des concentrations I et III. Ceci suggère que les espèces de Gönnersdorf sud-ouest, plus typiques des environnements boisés, datent d'une période plus tardive, au moment où la température a soudainement augmenté au tout début (GI-1e) de l'interstade tardiglaciaire (fig. 5).

\section{La faune d'Andernach 2 et 3}

En général, les espèces retrouvées à Andernach sont les mêmes que les plus communes de Gönnersdorf, avec quelques différences entre les diverses concentrations (tabl. 1). Comme les trois concentrations de matériel reconnues dans les limites des fouilles d'Andernach 2 sont très proches les unes des autres et qu'elles ont toutes été plus ou moins remaniées par des phénomènes anciens de remaniement sédimentaire et d'érosion ou par des perturbations récentes, l'attribution du matériel faunique à une concentration précise est quelquefois difficile sur leur pourtour. Ce problème ne se pose pas pour le matériel provenant du centre des concentrations ou bien du contenu des fosses, ce qui permet une caractérisation satisfaisante des différents contextes. Cependant, comme les deux plus grandes concentrations dallées ne sont pas complètement préservées, toute estimation du nombre minimum d'individus acquiert une valeur limitée. Pour en rester à une comparaison globale avec Gönnersdorf, on signalera que la zone fouillée d'environ $100 \mathrm{~m}^{2}$ à Andernach 2 a livré les restes d'au moins 12 chevaux, résultat en gros équivalent aux 13 individus provenant des $96 \mathrm{~m}^{2}$ de la concentration I de Gönnersdorf. Les autres espèces sont moins courantes, comme le renne qui n'est pas représenté par plus de trois individus. Ce calcul ne prend pas en compte les incisives modifiées, qui proviennent d'au moins huit individus, peut-être sans relation avec les activités de chasse réalisées pendant l'occupation du site. Le renard polaire est représenté au minimum par cinq ou sept individus, estimés sur la base soit du squelette post-crânien, soit de la dentition, c'est-à-dire par un nombre bien inférieur à celui de la concentration I de Gönnersdorf. Le lièvre, le lagopède, le corbeau et l'oie sont tous représentés par au moins deux individus.

La plupart des espèces retrouvées à Andernach sont présentes dans la grande structure dallée appelée concentration I. Elles comprennent le mammouth (seulement représenté à Andernach par de l'ivoire), le cheval, le renne, le renard polaire, le lièvre variable, le lagopède (attesté par un seul os), le cygne, l'oie et le saumon ou truite de mer. Le cerf est seulement présent sous forme de deux canines perforées (comme dans la concentration I de Gönnersdorf).

La faune de la concentration II, non dallée, est similaire à celle de la concentration $\mathrm{I}$, à condition de substituer aux restes de cygnes et d'oies ceux du corbeau et des lagopèdes et d'ajouter une autre espèce de poisson, l'ombre. La concentration II s'étend autour d'une fissure ouverte à l'époque de l'occupation et elle semble correspondre à une zone spécialisée dans la fabrication et le raffûtage des burins, utilisés probablement pour le travail de l'ivoire. On ignore si tout le matériel osseux découvert dans la fissure est en relation avec les activités qui se déroulèrent à l'origine dans la concentration II, ou bien s'il s'agit de déchets de boucherie jetés ou glissés par la suite par effet de l'érosion dans la fissure.

La faune de la petite zone appelée concentration III, qui a échappé à la destruction, est presque identique à celle de la concentration I. Il y a tout de même une petite différence qui concerne la présence de trois incisives d'un grand bovidé aménagées en parure par enlèvement de leurs racines. Des incisives découpées de renne sont aussi présentes, mais on n'a trouvé aucune incisive de cerf (comme dans la concentration II de Gönnersdorf) ou canine du même animal (comme dans la concentration I d'Andernach et la concentration I de Gönnersdorf).

Une description détaillée de la faune de la concentration IV n'est pas encore possible. Il semble que cette concentration soit reliée de près à la concentration II et qu'elle corresponde à la structure d'occupation principale dont la concentration II constituerait alors une zone satellite spécialisée. Les espèces présentes dans cette concentration IV ressemblent à celles des autres parties du site, mais elles n'ont pas encore été quantifiées (tabl. 1; Bergmann et Holzkämper, 2002).

\section{Saisonnalité des occupations magdaléniennes}

Les données de saisonnalité provenant de l'analyse des restes fauniques d'Andernach et les résultats 
préliminaires concernant Gönnersdorf suggèrent que les deux sites ont été occupés à plusieurs reprises pendant l'année.

Les données concernant le stade d'éruption dentaire des dents de chevaux et de rennes suggèrent une occupation d'automne/hiver pour les concentrations I et III d'Andernach. Les stades d'éruption dentaire du renne et du loup de la concentration I de Gönnersdorf suggèrent l'hiver, comme l'indique aussi la présence de lotte de rivière (Lota lota) (Poplin, 1976). Cette hypothèse d'une occupation pendant la saison froide de la concentration I et probablement de la III est également confortée par la présence d'ossements de fœtus de cheval de 3 à 4 mois. La présence en grande quantité de restes de renards polaires dans la concentration I pourrait être interprétée comme l'indication d'un piégeage hivernal de ces animaux pour leurs peaux. La présence d'oiseaux migrateurs (oie et/ou cygne) dans plusieurs concentrations des deux sites pourrait aussi suggérer une occupation d'automne/hiver si ces espèces avaient alors des comportements migratoires analogues à ceux d'aujourd'hui.

Pour la concentration II de Gönnersdorf, c'est une occupation de printemps et/ou d'été que suggère la découverte d'ossements de fœetus de cheval à un stade de développement plus avancé que dans la concentration I, ainsi que la présence de sabots de jeunes poulains.
À Andernach, de nombreuses vertèbres de grands salmonidés adultes (jusqu'à $1 \mathrm{~m}$ et plus) appartiennent clairement à des poissons anadromes et peuvent probablement être interprétées comme les restes d'individus capturés pendant le printemps et/ou l'été, au cours des remontées de la rivière pour le frai. Tandis que la majorité des restes provient de la concentration II, deux vertèbres d'un très grand salmonidé étaient situées dans une fosse de la concentration I, qui contenait aussi les dents d'un jeune cheval tué en automne. Il est possible que l'analyse faunique en cours clarifie quelques-unes des questions encore en suspens. D'ores et déjà, il est clair que Gönnersdorf et Andernach sont des sites dont l'histoire complexe s'étend sur de longues périodes de temps et recouvre différentes saisons de l'année.

\section{La faune des occupations à Federmesser}

Quelques sites attribués à la culture des groupes à Federmesser présentent une faune relativement diversifiée (tabl. 2), avec la présence d'une certaine variété de mammifères et parfois d'autres espèces, les uns et les autres étant souvent représentés par plusieurs individus. La faune de quelques autres sites est pratiquement monospécifique et, dans ce cas, l'espèce présente est le cerf.

\begin{tabular}{|c|c|c|c|c|c|c|c|c|}
\hline & AN2-FMG & Bad Breisig & Boppard & Kettig & $\mathrm{NiBi} 1$ & $\mathrm{NiBi} 2$ & $\mathrm{NiBi} 4$ & Urbar \\
\hline Saisonnalité & $\begin{array}{l}\text { Printemps/ } \\
\text { été ? }\end{array}$ & $\begin{array}{c}\text { Automnel } \\
\text { hiver? }\end{array}$ & $\begin{array}{l}\text { Printemps/ } \\
\text { été? }\end{array}$ & $\begin{array}{c}\text { Étél } \\
\text { automne? }\end{array}$ & - & - & $\begin{array}{c}\text { Hiver/ } \\
\text { printemps? }\end{array}$ & $\begin{array}{l}\text { Automnel } \\
\text { hiver? }\end{array}$ \\
\hline $\begin{array}{l}\text { Matières premières/ } \\
\text { organisation spatiale }\end{array}$ & $\begin{array}{c}\text { Variées, } \\
\text { non centralisée }\end{array}$ & $\begin{array}{l}\text { Peu variées, } \\
\text { centralisée }\end{array}$ & $\begin{array}{l}\text { Peu varièes, } \\
\text { centraliséee }\end{array}$ & $\begin{array}{c}\text { Varièes, } \\
\text { non centralisée }\end{array}$ & $\begin{array}{l}\text { Peu variées, } \\
\text { centralisée }\end{array}$ & $\begin{array}{c}\text { Variées, } \\
\text { non centralisée }\end{array}$ & $\begin{array}{l}\text { Peu varièes, } \\
\text { centralisée }\end{array}$ & $\begin{array}{l}\text { Peu variées, } \\
\text { centralisée }\end{array}$ \\
\hline $\begin{array}{l}\text { Élan } \\
\text { (Alces alces) }\end{array}$ & $\mathrm{NMI}=1$ & & & & $\begin{array}{c}\text { Association } \\
\text { incertaine }\end{array}$ & $\mathrm{NMI}=2$ & & \\
\hline $\begin{array}{l}\text { Cerf. } \\
\text { (Cervus elaphus) }\end{array}$ & $\mathrm{NMI}=5$ & $\mathrm{NMI}=3$ & "Dominant" & $\mathrm{NMI}=8$ & $\mathrm{NMI}=3$ & $\mathrm{NMI}=2$ & $\mathrm{NMI}=4$ & $\mathrm{NMI}=8$ \\
\hline $\begin{array}{l}\text { Chevreuil } \\
\text { (Capreolus capreolus) }\end{array}$ & $\begin{array}{l}\text { Association } \\
\text { incertaine }\end{array}$ & $\mathrm{NMI}=1$ & & $\mathrm{NMI}=3$ & & & & \\
\hline $\begin{array}{l}\text { Boviné } \\
\text { (cf. Bos) }\end{array}$ & $\mathrm{NMI}=2$ & & & $N M I=2$ & $\begin{array}{c}\text { Association } \\
\text { incertaine }\end{array}$ & & & $\begin{array}{c}\text { Association } \\
\text { incertaine }\end{array}$ \\
\hline $\begin{array}{l}\text { Chamois } \\
\text { (Rupicapra rupicapra) }\end{array}$ & $\mathrm{NMI}=2$ & & & & & & & \\
\hline Bouquetin (Capra ibex) & & & & & & & Présent & \\
\hline $\begin{array}{l}\text { Cheval } \\
\text { (Equis sp.) }\end{array}$ & $\begin{array}{l}\text { Association } \\
\text { incertaine }\end{array}$ & $\mathrm{NMI}=1$ & & $\mathrm{NMI}=3$ & & $\begin{array}{l}\text { Assocjation } \\
\text { incertaine }\end{array}$ & & \\
\hline $\begin{array}{l}\text { Sanglier } \\
\text { (Sus scrofa) }\end{array}$ & & & Présent & & & & & \\
\hline $\begin{array}{l}\text { Ours brun } \\
\text { (Ursus arctos) }\end{array}$ & & & & $\begin{array}{l}\text { Association } \\
\text { incertaine }\end{array}$ & & & & \\
\hline $\begin{array}{l}\text { Loup } \\
\text { (Canis hupus) }\end{array}$ & & & & $\begin{array}{l}\text { Association } \\
\text { incertaine }\end{array}$ & & & & \\
\hline $\begin{array}{l}\text { Renard roux } \\
\text { (Vulpes vulpes) }\end{array}$ & & $\begin{array}{c}\text { Association } \\
\text { incertaine }\end{array}$ & & $\begin{array}{c}\text { Association } \\
\text { incertaine }\end{array}$ & & & & \\
\hline $\begin{array}{l}\text { Blaireau } \\
\text { (Meles meles) }\end{array}$ & & & & & $\begin{array}{c}\text { Association } \\
\text { incertaine }\end{array}$ & & & \\
\hline $\begin{array}{l}\text { Carnivore (Canis sp./ } \\
\text { Meles meles) }\end{array}$ & & $\begin{array}{c}\text { Association } \\
\text { incertaine }\end{array}$ & & $\begin{array}{c}\text { Association } \\
\text { incertaine }\end{array}$ & & & & \\
\hline $\begin{array}{l}\text { Martre } \\
\text { (Martes sp.) }\end{array}$ & & & & $\begin{array}{l}\text { Association } \\
\text { incertaine }\end{array}$ & & & & \\
\hline Castor (Castor fiber) & $\mathrm{NMI}=2$ & & & $\mathrm{NMI}=2$ & & Présent & & \\
\hline $\begin{array}{l}\text { Lagomorphe } \\
\text { (LepusiOryctolagus) }\end{array}$ & & $\begin{array}{c}\text { Association } \\
\text { incertaine }\end{array}$ & & & & & & \\
\hline $\begin{array}{l}\text { Brochet } \\
\text { (Esox lucius) }\end{array}$ & Os nombreux & & & $\begin{array}{l}\text { Association } \\
\text { incertaine }\end{array}$ & & & & \\
\hline $\begin{array}{l}\text { Chevenne } \\
\text { (Leuciscus cephalus) }\end{array}$ & Os nombreux & & & & & & & \\
\hline $\begin{array}{l}\text { Cyprinide } \\
\text { (Leuciscus sp.) }\end{array}$ & Os nombreux & & & $\begin{array}{c}\text { Association } \\
\text { incertaine }\end{array}$ & & & & \\
\hline $\begin{array}{l}\text { Chabot } \\
\text { (Cottus gobio) }\end{array}$ & $\begin{array}{l}\text { Association } \\
\text { incertaine }\end{array}$ & $\begin{array}{c}\text { Association } \\
\text { incertaine }\end{array}$ & & & & & & \\
\hline Poisson indet. & & & Présent & & & & & \\
\hline
\end{tabular}

Tabl. 2 - Assemblages de faune découverts sur les occupations des groupes à Federmesser de Rhénanie centrale. Résultats provisoires issus d'études en cours. 
La faune de l'horizon à Federmesser d'Andernach 2 (AN2 FMG) est variée, avec une série de grands et petits mammifères (Street, 1993). On trouve au moins cinq cerfs (Cervus elaphus), deux spécimens de chamois (Rupicapra rupicapra), deux de castors (Castor fiber) et un grand boviné (probablement Bos primigenius), en compagnie de l'élan (Alces alces) et peut-être quelques vestiges très peu nombreux de chevreuil (Capreolus capreolus) et de cheval (Equus sp.). Les vestiges de poisson comprennent beaucoup d'ossements et de dents de brochet (Esox lucius) et de chevesne (Leuciscus cephalus). Des indices montrent qu'une partie de la faune a été chassée au printemps ou en été.

La faune de Kettig est très diversifiée et plusieurs espèces carnivores en font partie (Baales, 2002). On y trouve le cerf, le chevreuil, un grand boviné (probablement Bos primigenius), le cheval, le castor, l'ours brun (Ursus arctos), le loup (Canis lupus), le renard roux (Vulpes vulpes) et la martre (Martes). Comme à Andernach 2, il existe des indications de chasse estivale et/ou automnale. Une unique pointe à barbelure gracile en bois de cervidé pourrait évoquer des activités de pêche. La faune de la concentration NiBi II à Niederbieber est aussi plutôt diversifiée et les espèces sont à peu près les mêmes que celles qui ont été retrouvées à
Andernach 2 (AN2 FMG) et Kettig, c'est-à-dire le cerf, l'élan, le cheval et le castor.

Contrairement aux sites précédents, la faune retrouvée à Urbar est presque monospécifique, avec au moins sept cerfs identifiés dans la zone fouillée (Baales et al., 1998). Plutôt qu'un déchet de consommation, le métapode d'un grand boviné pourrait avoir été utilisé comme outil, ou bien correspondre à une réserve de matière brute. Il existe des indices montrant que les cerfs d'Urbar ont été tués en automne ou en hiver.

La plupart des restes fauniques de la concentration NiBi I de Niederbieber ont aussi été attribués au cerf. On a retrouvé également un os du pied d'élan, un fragment de tibia attribué au cheval ainsi qu'une mandibule et une dent inférieure de blaireau (Meles meles). Il est possible que les ossements de l'unique élan et des chevaux correspondent à des restes dispersés depuis la périphérie des concentrations adjacentes et que les restes de blaireau soient intrusifs et sans relation avec une activité humaine. À NiBi IV, qui peut être relié directement à NiBi I par des remontages lithiques, on a retrouvé beaucoup de restes de cerfs et des fragments de dents d'un capridé, en l'occurrence probablement d'un bouquetin (Capra ibex). Il y a dans la concentration NiBi IV quelques preuves d'occupation hivernale.
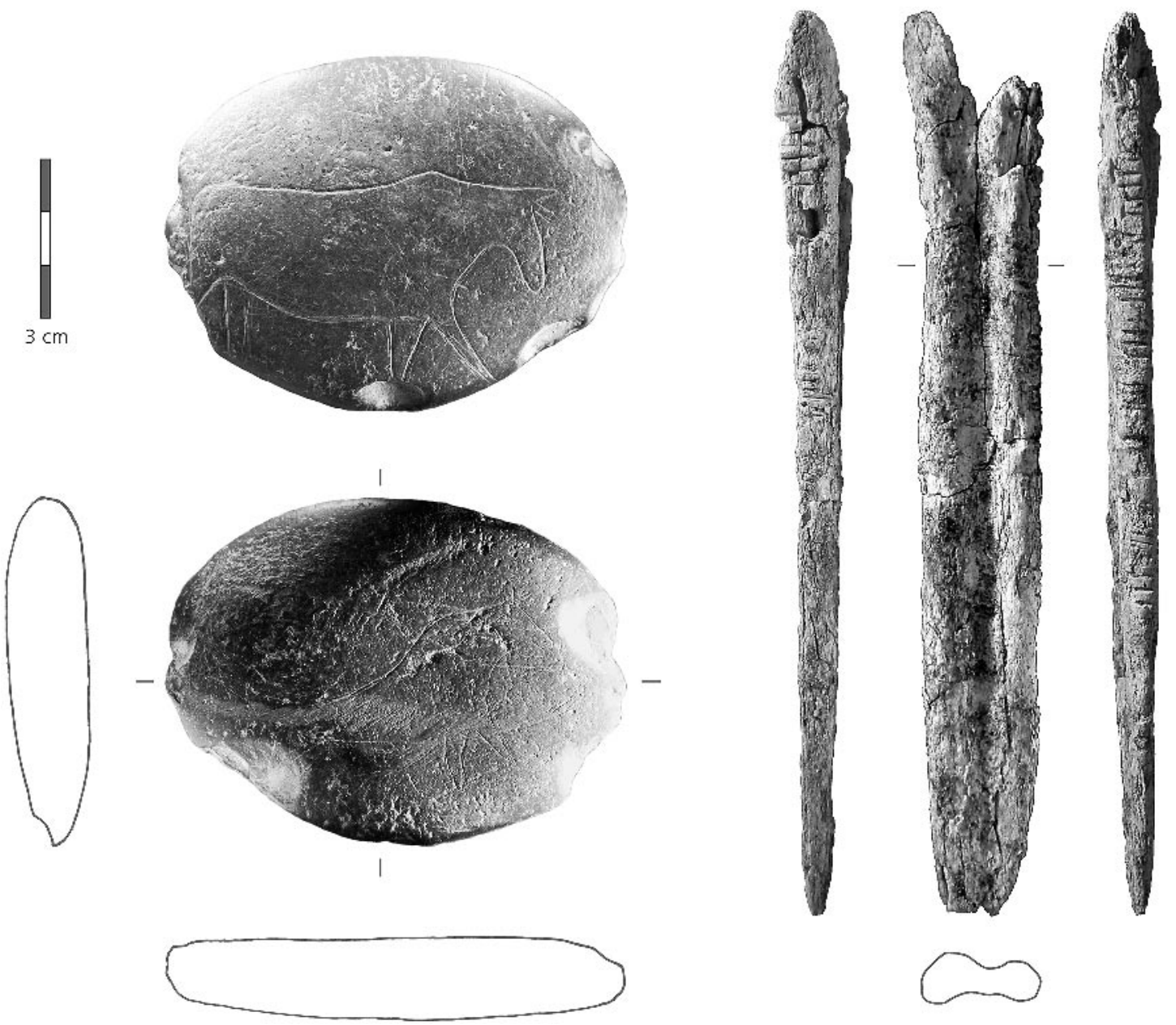

Fig. 6 - À gauche : galet en schiste induré de Windeck (vallée du Sieg) avec des traces d'usage comme retouchoir et deux silhouettes d'animaux gravées sur les deux faces de l'objet; à droite : lissoir fabriqué à partir d'un métapode de cerf provenant du site de Boppard (Rhénanie centrale) montrant des incisions régulières le long des deux côtés. 
Les autres assemblages fauniques de Niederbieber sont moins informatifs. À NiBi V, le peu de vestiges fauniques préservés atteste la présence du cerf, d'un grand boviné et peut-être de l'élan. Seuls trois restes fauniques de NiBi VI peuvent être identifiés comme appartenant probablement au cerf. Parmi la vingtaine de restes provenant de NiBi VII, presque tous sont des fragments de dents attribuées au cerf - ou à un cervidé, sans plus de précision - au castor et au sanglier (Sus scrofa).

Le matériel faunique d'Andernach 3 (AN3-FMG) présente un mauvais état de conservation, mais l'identification provisoire de quelques restes suggère au moins que le cerf était présent.

La conservation de l'os est également plutôt mauvaise à Bad Breisig, mais l'assemblage offre tout de même une image assez détaillée d'une faune chassée à caractère tempéré. Le cerf est représenté par au moins trois individus. Les restes de chevreuils et de chevaux sont également présents et leur exploitation par l'Homme est certaine. Quelques éléments suggèrent une occupation d'automne ou d'hiver. Les autres vestiges incluent le renard roux, probablement le blaireau et le lièvre (Lepus sp.), ainsi qu'un poisson, le chabot (Cottus gobio). Il n'est pas impossible que ces autres vestiges n'aient aucune relation avec les activités humaines.

Les vestiges fauniques de Boppard sont principalement attribués au cerf, auxquels s'ajoutent des fragments de dents de sanglier (Sus scrofa) et plusieurs minuscules vertèbres de poisson, apparemment brûlées. Le degré d'usure de quelques dents de sangliers suggère la chasse de cet animal durant le printemps et/ou l'été, mais il reste à savoir si le petit nombre de fragments de dents de cette espèce, ici comme à NiBi VII, appartient réellement à la faune locale contemporaine, ou s'il s'agit d'un matériau importé ou collecté comme une curiosité. Un métapode de cerf travaillé et orné a été découvert à Boppard, et c'est une pièce unique pour le Tardiglaciaire de Rhénanie (fig. 6). Son décor trouve des parallèles dans le Paléolithique supérieur d'Europe de l'Ouest (Wenzel, 2004; Wenzel et Álvarez Fernández, 2004), tandis que l'objet lui-même ressemble aux «lissoirs » du Mésolithique holocène.

\section{Matières premières, territoires et contacts}

En général, la Rhénanie centrale est pauvre en matières premières adaptées à la production d'outils lithiques, notamment ceux qui requièrent une qualité minimale. Les seules exceptions sont un quartzite tertiaire à grain fin, ou des formes indurées de schistes. L'étude des industries lithiques montre que les matières premières allochtones (très souvent du silex du Crétacé) ont été transportées sur de grandes distances (fig. 7) et cette analyse met en évidence des genres de mobilité complexes. Elle nous apporte des informations sur le rayon d'activité d'un groupe dans différentes directions et peut donc indiquer l'étendue globale des territoires.
L'obtention et l'usage des matières premières en Rhénanie durant le Tardiglaciaire ont considérablement varié (Floss, 1994). Cette variabilité transparaît à la fois de sites en sites magdaléniens ou à Federmesser et, à un niveau plus général, entre les deux groupes culturels. Ces différences se manifestent dans la diversité des spectres de matières premières et dans les quantités variables de matières premières importées de loin (fig. 8 et 9 ).

Les matières premières lithiques utilisées dans les sites tardiglaciaires de Rhénanie centrale se répartissent, en gros, en trois groupes. Les premières sont disponibles localement et ont été obtenues dans les affleurements ou parmi les galets de rivière. Le matériau le plus fréquent dans le groupe 1 est le schiste induré (Kielselschiefer - KS).

Le second groupe (2) comprend des matières premières disponibles à l'échelle régionale dans un rayon d'environ $30 \mathrm{~km}$ (fig. 7). Elles comprennent: 1) la calcédoine venant d'un affleurement bien connu à Muffendorf (Muf) près de Bonn, à 35-30 km au nordouest, une matière première employée uniquement par les groupes à Federmesser; 2) un quartzite tertiaire (TQ). On trouve ce dernier en de nombreux endroits de la région sous forme d'affleurements et d'épandages de blocs (Floss, 1994), mais on ne connaît pas les lieux exacts où étaient obtenues les variétés de très bonne qualité exploitées pendant le Tardiglaciaire.

Le troisième groupe (3) comprend des matières premières lithiques allochtones venant de sources beaucoup plus éloignées de la Rhénanie centrale (plus de $90 \mathrm{~km}$ ). Ceci démontre l'existence de relations avec quatre grandes régions situées aux quatre points cardinaux (fig. 7).

Le sous-groupe 3a comprend du silex d'Europe de l'Ouest (WF). Il vient des formations primaires de craie du Crétacé, dans la zone frontière belgo-germanoluxembourgeoise, entre Liège, Maastricht et Aix-laChapelle, à quelque $120-130 \mathrm{~km}$ en direction de l'ouest et du nord-ouest, ou bien il a été recueilli sous forme de galets dans des terrasses fluviatiles de la partie ouest de la Basse-Rhénanie. Dans les assemblages magdaléniens de Rhénanie centrale, ces silex d'Europe de l'Ouest sont associés à une forme de quartzite à grain fin «paléozoïque» (terme peut-être erroné : Heuschen, 1997) - PQ -, et dont la provenance géographique est probablement similaire.

Le sous-groupe $3 \mathrm{~b}$ est constitué de silex de la Baltique, dont les gîtes les plus proches sont les moraines laissées par l'avant-dernière glaciation et parvenues vers le sud jusqu'à la région immédiatement au nord de la rivière Ruhr, à quelque $100 \mathrm{~km}$ au nord de la Rhénanie centrale.

Tandis que les sous-groupes $3 a$ et $3 b$ indiquent des relations vers l'ouest et le nord, le sous-groupe $3 \mathrm{c}$ témoigne de relations avec le sud. Le sous-groupe 3c-1 comprend des matières premières importées en Rhénanie centrale depuis l'est et le sud-est, très probablement depuis la basse vallée du Main et le bassin de Mayence, à quelque 80 ou $100 \mathrm{~km}$ de la Rhénanie centrale. Il comprend une variété de calcédoine $(\mathrm{CH})$ utilisée uniquement durant le Magdalénien et des 


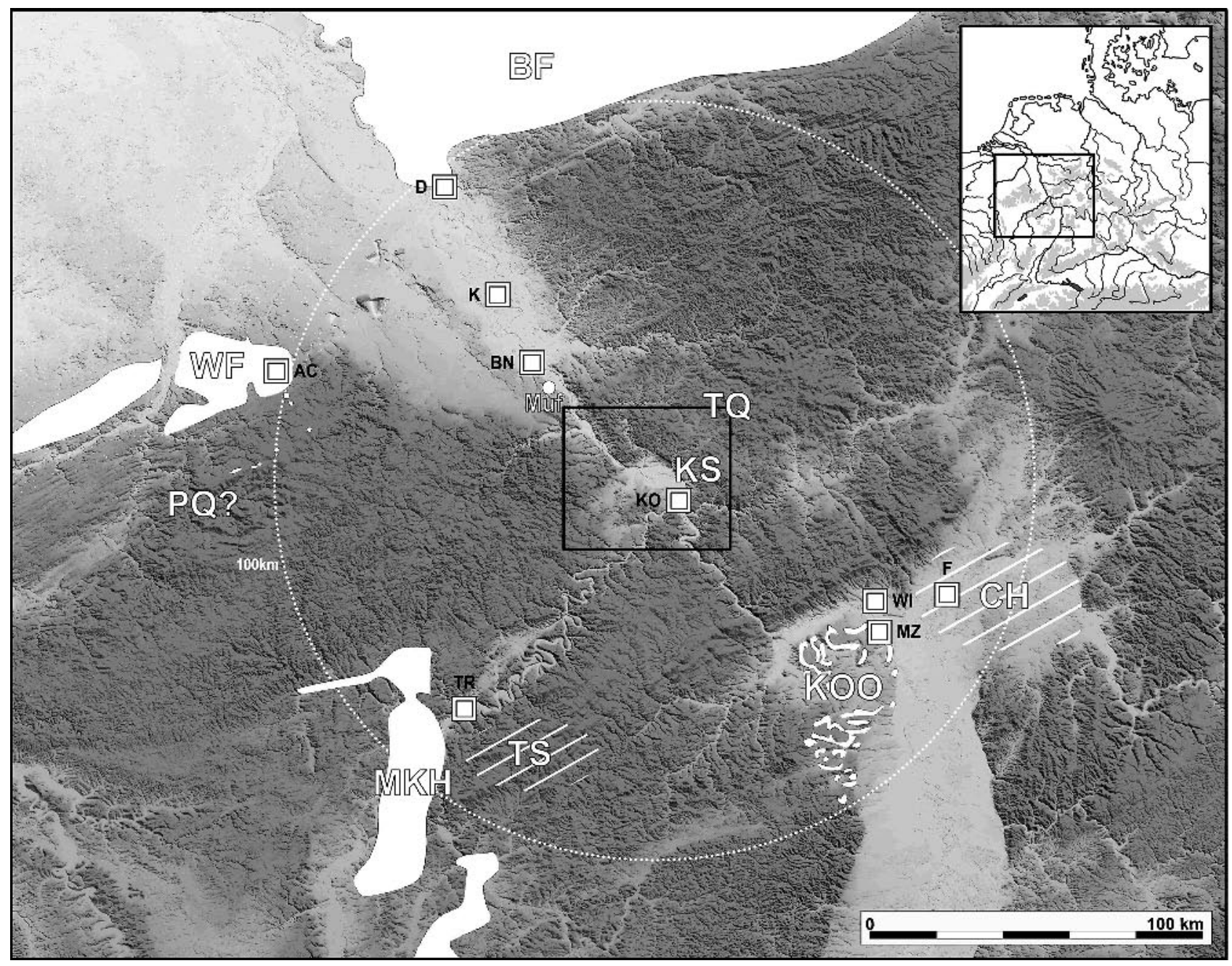

Fig. 7 - Carte de provenance des matières premières lithiques découvertes sur les sites tardiglaciaires de Rhénanie centrale (voir aussi fig. 8). BF : silex crétacé «Baltique» provenant des dépôts de moraines; KS : schiste induré; TQ : quartzites tertiaires; $\mathrm{CH}$ : calcédoine; KOO : oolithes indurées; TS : schiste argileux; MKH : cherts du Triassique (Muschelkalkhornstein); PQ : quartzite «paléozoïque»; WF : silex crétacé provenant de la craie ou remanié dans des terrasses fluviatiles; Muf : calcédoine de Muffendorf. AC : Aix-la-Chapelle; BN : Bonn; D : Düsseldorf; F : Frankfurt am Main; $\mathrm{K}$ : Cologne; KO : Coblence; MZ : Mayence; TR : Trèves; WI : Wiesbaden. Le cercle blanc désigne un rayon de $100 \mathrm{~km}$ à partir du centre du bassin de Neuwied. Le rectangle noir au centre délimite la région illustrée par la fig. 1.

formes d'oolithes indurées (Kieseloolith: KOO). Les matières premières du sous-groupe $3 \mathrm{c}-2$ ont pour origine des gîtes du sud-ouest de la Rhénanie centrale, indiquant peut-être une voie de communication le long des vallées de la Moselle et de la Nahe. À ce groupe appartiennent les cherts du Triassique (Muschelkalkhornstein: MKH) et un schiste argileux (Tonstein de type Schaumberg: TS) utilisés par les groupes à $\mathrm{Fe}$ dermesser.

En bref, les matières premières lithiques communes aux Magdaléniens et aux groupes à Federmesser viennent de sources situées au nord-ouest et au nord, tandis que les matières premières venant de l'est et sud-est (3c-1) et du sud-ouest (3c-2) ont été utilisées exclusivement durant l'une ou l'autre phase.

Si on s'attache uniquement aux matières premières allochtones, il est frappant de constater que les assemblages magdaléniens comme ceux à Federmesser sont caractérisés par des matières premières venant de l'ouest et du nord-ouest (WF et PQ) bien plus que par n'importe quelle autre matière première. La seconde composante la plus importante est le silex de la Baltique importé du nord, mais les sites où cette matière première domine exclusivement restent rares.

Les matériaux méridionaux, importés de l'est et du sud-est durant le Magdalénien, et du sud-ouest durant la phase à Federmesser, jouent en général un rôle mineur. Ils ne sont présents en quantité appréciable que dans quelques industries magdaléniennes (concentration III à Andernach, concentrations III et IV à Gönnersdorf) et ils sont extrêmement rares dans les sites à Federmesser (NiBi XVI, NiBi XI). Il est peut-être significatif qu'une combinaison de matières premières importées à la fois du nord et du sud (groupe 3c-2) n'apparaisse pas dans ces sites à Federmesser, les deux composantes étant mutuellement exclusives.

Les matières premières allochtones venant de l'ouest et du nord-ouest se rencontrent plus fréquemment dans les sites à l'ouest du Rhin. Bien qu'elles soient fréquentes dans les assemblages des différentes 
concentrations magdaléniennes de Gönnersdorf, les quantités en présence sont bien plus faibles que dans le Magdalénien d'Andernach. Seuls parmi les sites à Federmesser, Kettig et Andernach, tous deux à l'ouest du Rhin, ont livré une proportion élevée de silex ouesteuropéen, suivis par le site légèrement plus récent de Bad Breisig, également à l'ouest du Rhin.

\section{Précisions sur les matières premières du Magdalénien}

En général, la qualité des matières premières utilisées est élevée. C'est vrai pour les variétés de quartzite tertiaire disponibles dans la région et, encore plus, pour les matières premières allochtones qui sont, dans certains cas, les matériaux dominants au sein d'une concentration de vestiges. Le silex du Crétacé a été apporté ou bien depuis les affleurements du bassin de la Meuse, à au moins 100 km à l'ouest et nord-ouest, ou bien de dépôts morainiques à environ $100 \mathrm{~km} \mathrm{au}$ nord, tandis qu'il semble que la calcédoine et l'oolithe indurée proviennent de quelque 80 à $120 \mathrm{~km}$ au sud (fig. 7).

Certaines concentrations sont dominées par des matières premières lithiques allochtones telles les concentrations III et IV à Andernach et la concentration II à Gönnersdorf, où le silex occidental représente plus de $90 \%$ de l'assemblage lithique. Par contraste, les assemblages lithiques des concentrations magdaléniennes I et III d'Andernach-Martinsberg sont dominés par le quartzite tertiaire régional, tandis que d'autres assemblages (concentrations I, III, et IV de Gönnersdorf) présentent des spectres très diversifiés (fig. 8).

La présence des matières premières allochtones en Rhénanie centrale est probablement un bon indicateur des régions occupées ou traversées par les groupes magdaléniens à d'autres moments de l'année. On ne peut exclure que le silex de l'ouest et nord-ouest (3a) et du nord (3b) ainsi que les matières premières lithiques méridionales ( $3 \mathrm{c})$ aient été collectés durant un unique cycle de migration par un seul groupe, mais la diversité des régions concernées rend plus probable l'apport de ces matériaux par des gens différents. La co-occurrence de matières premières importées des deux origines dans une seule et même concentration (par exemple Gönnersdorf I et III) pourrait alors être interprétée en termes d'échanges entre différentes communautés humaines durant des occupations contemporaines, ou bien comme la preuve de phases distinctes de réoccupation.

Quant aux matières régionales, leur diversité dans une même concentration indique peut-être des expéditions brèves à partir de la Rhénanie centrale. Dans ce cas, une diversité élevée de matières premières lithiques reflète peut-être une durée relativement prolongée d'occupation. On peut aussi l'interpréter comme l'indice de plusieurs phases de réoccupation.

Le silex de bonne qualité d'Europe de l'Ouest est rarement présent sous forme de produits appartenant aux phases initiales de débitage et il paraît probable que cette matière première a été apportée dans les sites sous forme de nucléus ou de blocs préformés ou encore comme outils finis. Il est donc impossible de démontrer que la présence de matières premières allochtones en Rhénanie centrale est le résultat d'expéditions spécifiques destinées à s'en procurer, mais on peut au moins affirmer que les Magdaléniens prenaient soin de sélectionner le meilleur matériau disponible quand le groupe (ou quelques-uns de ses membres) passai(en)t dans une région d'approvisionnement.

À une bien plus grande échelle, les coquilles d' Homalopoma sanguineum et de Dentalium trouvées dans les horizons magdaléniens d'Andernach et Gönnersdorf viennent de la Méditerranée ou du sud de la côte Atlantique française, à 800-1000 km de la Rhénanie (voir notamment Álvarez Fernandez, 2001). Ces trouvailles ne correspondent probablement pas seulement à une simple parure mais à des objets dont la valeur symbolique était liée à leur rareté. Elles montrent que la Rhénanie magdalénienne était intégrée aux réseaux sociaux d'échange d'objets précieux à longue distance.

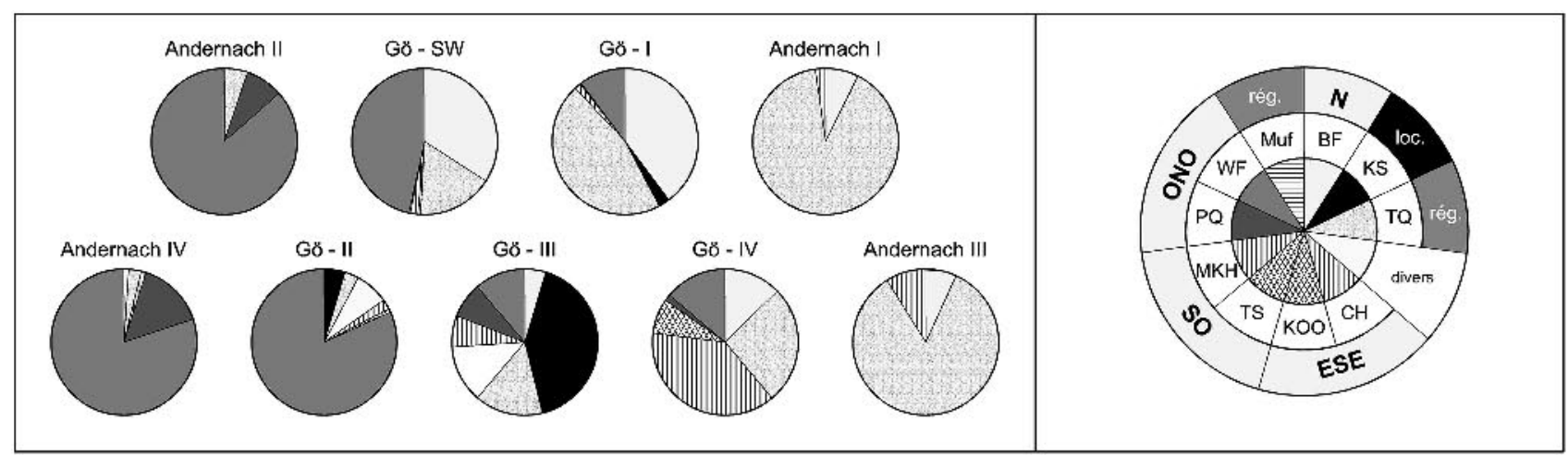

Fig. 8 - Gamme des matières premières utilisées sur les sites magdaléniens de Gönnersdorf (Gö concentrations I-IV et secteur sud-ouest) et d'AndernachMartinsberg (concentrations I-IV). Le diagramme par secteurs explicite les trames utilisées pour les différentes matières premières (les deux cercles au centre); ces matières sont disposées selon les points cardinaux qui indiquent leur origine (cercle périphérique). BF : silex crétacé «Baltique» provenant des dépôts de moraines; KS : schiste induré; TQ : quartzites tertiaires; $\mathrm{CH}$ : calcédoine; KOO : oolithes indurées; TS : schiste argileux ; MKH : cherts du Triassique (Muschelkalkhornstein); PQ : quartzite «paléozoïque»; WF : silex crétacé provenant de la craie ou remanié dans des terrasses fluviatiles; Muf : calcédoine de Muffendorf. NB : les matières TS, MKH et Muf n'ont pas été utilisées pendant le Magdalénien. Pour la concentration IV d'Andernach, le décompte concerne uniquement les outils retouchés (d'après Holzkämper, 1999); données sur la concentration IV de Gönnersdorf d'après Moseler, 2006; pour toutes les autres concentrations, données d'après Floss, 1994. 
Les gravures de phoques trouvées à Gönnersdorf et Andernach (Bosinski et Bosinski, 1991) suggèrent aussi que quelques membres au moins des groupes magdaléniens ont pu voyager sur de très longues distances durant leur vie. Certes, on a parfois suggéré que ces animaux avaient pu remonter le Rhin jusqu'en Rhénanie centrale, qui était beaucoup plus éloignée de la côte durant le Tardiglaciaire que maintenant, mais aucun os appartenant à cette espèce n'y a jamais été retrouvé. Il est donc tout aussi vraisemblable que ces animaux aient été observés par les artistes sur les rivages.

\section{Précisions sur les matières premières des groupes à Federmesser}

Certaines des régions qui fournissaient des matières premières régionales et allochtones durant le Magdalénien ont continué à être visitées durant le Paléolithique final, mais la qualité des matériaux obtenus est devenue beaucoup moins importante. Le silex du Crétacé arrive désormais dans les sites de Rhénanie centrale sous forme de nodules non préparés et de galets de qualité variable (Floss, 1994). Cet état de fait propre aux groupes à Federmesser reflète des techniques beaucoup moins élaborées pour la fabrication des outils et suggère que la matière première était simplement collectée de façon opportuniste durant le cycle annuel de déplacements. La présence d'une grande variété de matériaux allochtones montre que les groupes à Federmesser couvraient des territoires aussi étendus que durant le Magdalénien (fig. 7). Les nouveaux matériaux, schistes argileux et cherts du Triassique, suggèrent des contacts accrus avec le sud-ouest, tandis que les matériaux originaires du sud-est sont désormais absents.

On possède des descriptions précises pour quelques assemblages des groupes à Federmesser qui ont fait l'objet d'analyses exhaustives, mais l'analyse de beaucoup d'autres (y compris ceux récupérés par tamisage à l'eau) n'est pas encore achevée, notamment à Niederbieber, où beaucoup d'unités spatiales distinctes ont pu être identifiées et pour lesquelles l'information n'est pas encore disponible (fig. 9).

Les spectres de matières premières de la plupart des assemblages à Federmesser sont dominés par des matériaux disponibles à l'échelle de la région (quartzite tertiaire et calcédoine de Muffendorf). Bien que la prépondérance du quartzite tertiaire régional caractérise un des modes d'approvisionnement typiques des groupes à Federmesser, ce mode était déjà attesté durant le Magdalénien (concentrations I et III d'Andernach). De la même façon, on trouve aussi des assemblages lithiques à Federmesser avec des matières premières très variées. On peut donc classer ces derniers en deux groupes (fig. 9).

Le premier est dominé par des industries comportant plus de $75 \%$ de matières premières régionales. Bien que ces assemblages se ressemblent beaucoup à première vue (d'un point de vue quantitatif), ils peuvent en réalité différer fortement (d'un point de vue qualitatif), si l'on prend en compte les différentes variétés et origines de la petite quantité de matériaux importés. Ce premier groupe (groupe 1), plutôt homogène, se divise donc en sites dominés par le quartzite tertiaire (TQ) - soit le sous groupe 1-TQ - et ceux dominés par la calcédoine (Muf) - sous-groupe 1-Muf. À Urbar, où l'assemblage est dominé par le quartzite tertiaire, les grattoirs unguiformes abondent parmi les outils (82\%). Le quartzite tertiaire à Bad Breisig (Grimm, 2004) comprend un grand nombre de nucléus (144), ce qui semble indiquer que cette matière première était accessible dans le voisinage immédiat du site et qu'elle pourrait être redéfinie dans ce cas comme une ressource locale. Par contraste, dans le site de Boppard, dont l'assemblage est également dominé par le quartzite, la petite quantité de silex du Crétacé du nord-ouest a de toute évidence été transportée sur une beaucoup plus longue distance que le même silex trouvé dans les sites du bassin de Neuwied. Le sous-groupe 1-Muf dominé par la calcédoine se rencontre uniquement à AndernachMartinsberg (AN3-FMG) et à Niederbieber (les deux zones interconnectées NiBi I et IV, ainsi qu'un grand nombre d'autres concentrations que l'on doit encore analyser de façon exhaustive). Il faut signaler que ces deux sites se trouvent sur la bordure nord du bassin de Neuwied et donc au plus près de Muffendorf.

Le second groupe d'assemblages (groupe 2), plus hétérogène, comprend des sites où les matières premières régionales représentent moins des deux-tiers de l'assemblage. Il peut être divisé, cette fois, en trois sous-groupes (fig. 9).

Le premier d'entre eux (sous-groupe 2-KS) présent à Niederbieber (NiBi XIV, XVI et XI) est caractérisé par l'utilisation plus ou moins intensive de schiste induré local, en association avec une grande variété de matières premières. Les assemblages du sous-groupe 2-WF à Kettig et Andernach-Martinsberg (AN2-FMG) contiennent une forte proportion de matières premières importées du nord-ouest. Andernach a livré des outils fabriqués dans cinq variétés différentes de silex du Crétacé du nord-ouest et probablement un seul nucléus en silex des moraines nordiques (33,2\% au total). À Kettig, le silex crétacé du nord-ouest représente jusqu'à $40 \%$ de l'assemblage. Les matériaux régionaux constituent le groupe le plus important à AN2-FMG : les deux variétés de quartzite tertiaire représentent respectivement $46,2 \%$ et $9,2 \%$. Ce matériau est moins représenté à Kettig (38\%).

Du schiste induré provenant d'une source à environ $100 \mathrm{~km}$ au sud-ouest constitue 6,52\% de l'assemblage d'Andernach-Martinsberg (AN2-FMG) et ce matériau est aussi présent à Kettig et à NiBi II. À Kettig, deux grattoirs unguiformes ont été produits dans des pierres semi-précieuses très colorées qui viennent d'affleurements du bassin de la Nahe à environ $80 \mathrm{~km}$ au sudouest (Baales, 2002). À AN2-FMG une très petite quantité d'oolithe indurée (moins de $1 \%$ ) présente, dans certains cas, un cortex roulé et correspond peutêtre à du matériel trouvé dans les graviers du Rhin plutôt que dans les gîtes primaires du bassin de Mayence. Les matériaux locaux jouent un rôle insignifiant à Andernach (AN2-FMG), mais le schiste induré représente près de $20 \%$ de l'assemblage à Kettig. 


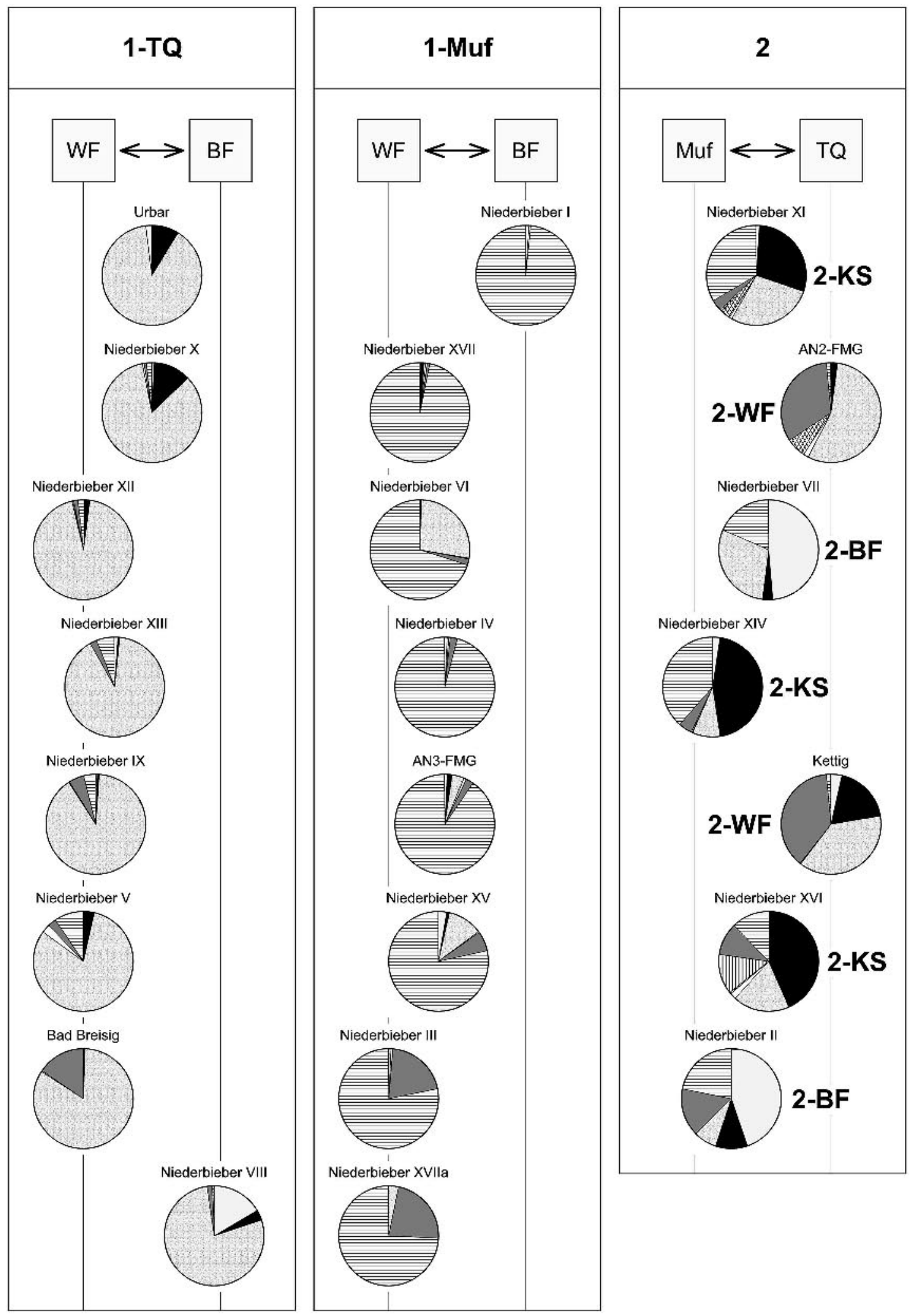

Fig. 9 - Gamme des matières premières utilisées sur les sites des groupes à Federmesser et classées selon les groupes décrits dans le texte. Pour la légende, voir fig. 8 (NB : les matières $\mathrm{CH}, \mathrm{KOO}$ et $\mathrm{PQ}$ n'ont pas été identifiées sur les sites des groupes à Federmesser). Dans les groupes 1-TQ et 1-Muf, les diagrammes sont disposés de haut en bas de façon à illustrer la diminution en proportion des matériaux locaux et régionaux; dans le groupe 2, c'est la proportion de matériaux régionaux qui décroît. Pour Andernach 3 FMG, le décompte concerne uniquement les outils retouchés (d'après Kegler, 2002); données sur Bad Breisig d'après Grimm, 2003; données sur Kettig d'après Baales, 2002; données sur Urbar et la concentration II de Niederbieber d'après Floss, 1994 ; pour toutes les autres concentrations de Niederbieber, d'après Gelhausen, en préparation. 
Le sous-groupe 2-BF, qu'on trouve seulement à Niederbieber, se caractérise par des assemblages (NiBi II et NiBi VII) dominés par le silex de la Baltique (44,8\% à 48,5\%) : il est remarquable que ce matériau abonde seulement dans des concentrations situées à l'extrême nord de la zone fouillée (c'est le cas aussi dans l'unité NiBi XIII). La calcédoine de Muffendorf, d'origine régionale, forme environ $20 \%$ des assemblages. Les proportions des autres matières premières, locales, régionales et allochtones, sont très variables dans les unités NiBi II et NiBi VII.

\section{L'ESPACE SOCIAL : DIMENSIONS ET ORGANISATION DES CAMPEMENTS ET DES STRUCTURES D'HABITAT}

\section{L'espace social des Magdaléniens}

Gönnersdorf et l'horizon magdalénien d'Andernach se caractérisent tous les deux par la présence de plusieurs concentrations de trouvailles distinctes. Sabine Eickhoff (1992) a effectué une analyse des structures d'habitat d'Andernach 2 (concentrations I, II et III) complétant des descriptions antérieures plus brèves (Veil, 1982b et 1984). Par ailleurs, de nombreuses publications ont fait connaître les différentes composantes du matériel archéologique (Höck, 1995; Tinnes, 1994 ; Àlvarez Fernández, 2001). Notons que certaines parties des concentrations II et III ont été sérieusement perturbées par l'érosion postérieure à la mise en place de l'horizon archéologique.

À Gönnersdorf, une première analyse spatiale de la concentration I a été publiée par le fouilleur, Gerhard Bosinski (1979). La partie sud-ouest du site (concentration SW), immédiatement adjacente à la concentration I, a été étudiée plus tard (Buschkämper, 1993). Quant aux concentrations III et IV situées au nord de la fouille, elles ont été analysées et publiées dans une monographie (Terberger, 1997), suivie d'une révision portant sur des détails de la concentration IV (Jöris et Terberger, 2001).

Une nouvelle analyse de la concentration IV a pris en compte la répartition spatiale des lieux de débitage (y compris la plus petite fraction tamisée à l'eau), au moyen d'une cartographie par SIG des densités et en intégrant les nouveaux résultats acquis par des remontages systématiques (Moseler, 2006). Cela a conduit à définir plus clairement l'organisation interne de la structure, tout en précisant la fonction de plusieurs zones extérieures qu'on peut maintenant intégrer dans un réseau de relations concrètes avec l'habitation (fig. 10).

La concentration II, la plus vaste, peut être subdivisée en deux sous-unités IIa et IIb, chacune localisée autour d'un groupe de fosses. L'analyse de la plus grande des deux (IIa) a servi de sujet de doctorat (Sensburg, 2004). Elle a montré que les petits ensembles de matière première lithique ne sont pas des dépôts de vestiges indépendants de IIa mais en sont partie intégrante et donc contemporains. Elle a aussi prouvé que l'analyse spatiale de ces déchets était nécessaire pour comprendre en profondeur l'organisation interne de telles structures d'habitat.

Dans quatre concentrations de Gönnersdorf et quatre d'Andernach, un certain nombre de fosses intentionnellement creusées a reçu diverses interprétations : trous de poteaux, foyers, fosses à cuire. Les concentrations I, IIa, IIb et III de Gönnersdorf et I, III et IV d'Andernach ont été interprétées comme des structures d'habitat closes et durables, qui ont demandé, dans certains cas, de rassembler plusieurs tonnes de pierres. Ces structures sont caractérisées par des pavages constitués de grandes dalles de schiste, de quartzite et d'autres roches, qui ont parfois conservé une coloration rouge due à l'ocre, ainsi que par des concentrations de débris lithiques taillés, des restes fauniques (fig. 11 et 12) et autres objets.

Deux structures de Gönnersdorf sans fosses (concentrations IV et SW) sont interprétées comme de possibles habitations démontables. La concentration II à Andernach a en son centre une fissure naturelle qui semble avoir été ouverte jusqu'à une profondeur de $2 \mathrm{~m}$ à l'époque de l'habitat. L'interprétation de cette structure reste problématique. Il paraît clair que les activités comprenaient la production et le ravivage répété de burins de silex, et peut-être le travail de l'ivoire, mais il n'est pas possible de dire s'il y avait ou non une structure d'habitat ou si c'était une aire d'activité extérieure.

L'interprétation de ces constructions, comme de l'ensemble des zones fouillées, procède de l'analyse détaillée de chaque catégorie de vestiges : les éléments de construction (dalles de schiste, quartzite, basalte, etc.), les assemblages lithiques et fauniques (ces derniers comprennent les restes osseux et les objets en os, bois de renne ou ivoire), les témoins d'expression artistique (gravures et sculptures), les charbons et autres témoins de combustion (dalles de pavage rubéfiées, blocs de quartz fissurés servant à faire bouillir de l'eau). Tous ces vestiges sont analysés de façon quantitative et qualitative afin de donner une définition statique ou descriptive du caractère de l'occupation magdalénienne. L'analyse spatiale, qui comprend entre autres des études intensives sur les remontages de diverses catégories de vestiges (dalles de schiste et de quartzite, quartz, industrie lithique et vestiges fauniques) donne accès à la dimension temporelle complexe des activités puis à la reconstruction des processus dynamiques.

Par contraste avec les sites magdaléniens français du Bassin parisien et les sites suisses de Monruz et Champréveyres dont on a discuté durant la table ronde, ni Gönnersdorf ni Andernach ne livrent de preuves de stratification de sols d'habitat qui permettraient de reconnaître des phases d'occupation distinctes ou une certaine profondeur de temps. Toutefois, un certain nombre d'indices laisse penser que Gönnersdorf et Andernach ont été occupés durant une longue période et probablement de façon répétée. Ces indices comprennent: l'accumulation d'un grand nombre de vestiges diversifiés, la grande quantité de ressources alimentaires traitées indiquée par les restes de faune, la large gamme d'activités utilitaires (de construction, 


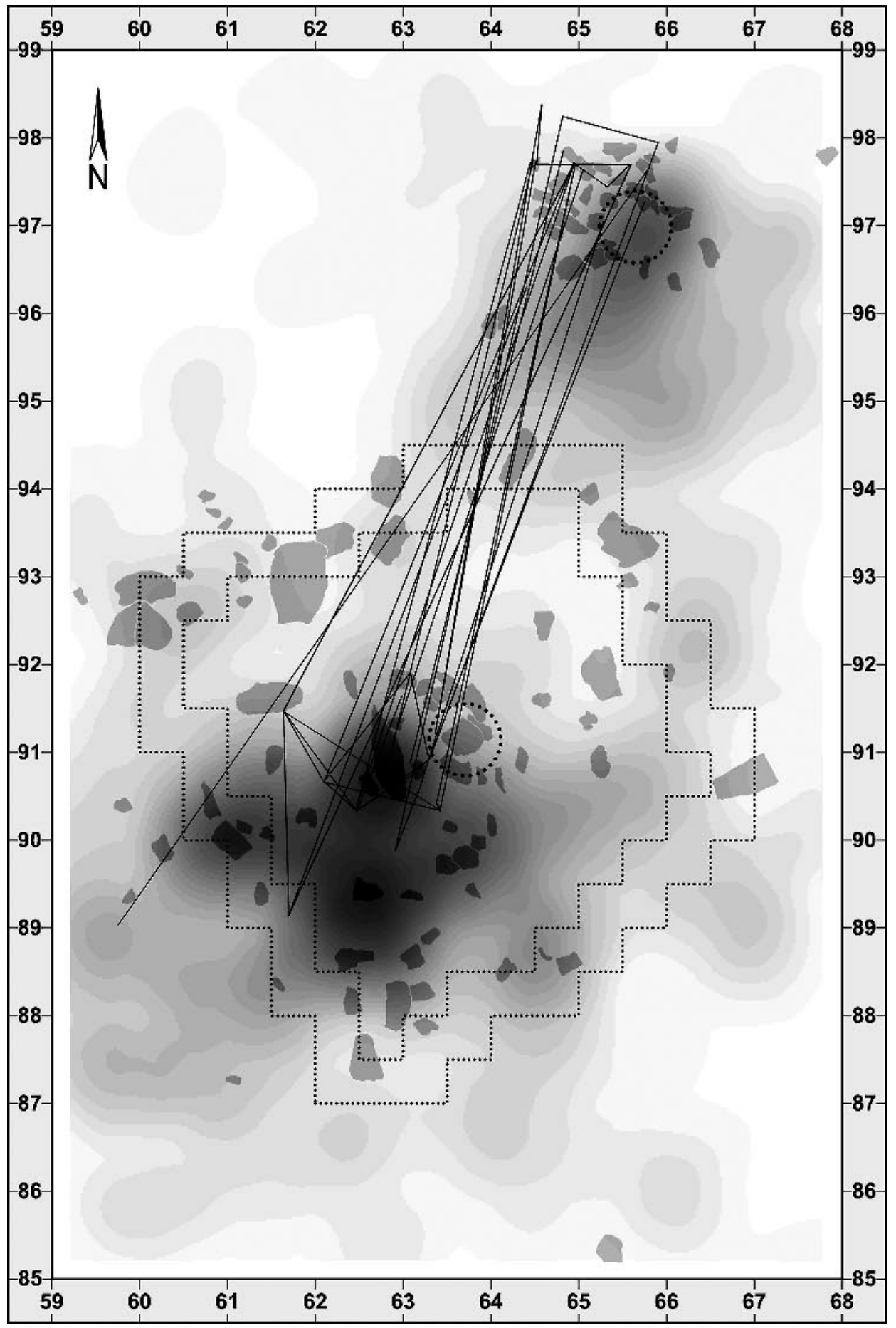

Fig. 10 - La concentration IV de Gönnersdorf. Carte de densité pour tous les artefacts en calcédoine. En arrièreplan figurent les plaques et dalles de pierre de plus de $20 \mathrm{~cm}$ (Moseler, 2006). Les liaisons par remontage concernent les éléments en quartzite (d'après Terberger, 1997) et relient une zone de combustion au nord avec une autre située au centre de l'habitation (concentration IV).

de production d'outils par exemple...), les nombreuses activités non utilitaires (production de parure, présence massive de témoins artistiques) ainsi que les preuves que ces deux sites se trouvaient au centre d'un réseau de communication s'étendant sur plusieurs centaines de $\mathrm{km}$ (comme l'indiquent les matériaux lithiques allochtones et les parures). Une solution pour mieux apprécier la durée et la chronologie relative pourrait provenir de la «stratigraphie horizontale» déduite des remontages et l'analyse spatiale par SIG.

Ni Gönnersdorf ni Andernach ne livrent de foyers aux formes bien définies et aisément reconnaissables comme ceux des sites magdaléniens du Bassin parisien (Audouze, ce volume; Julien, ce volume; Olive et Pigeot, ce volume) ou comme les épandages de charbons tels qu'ils subsistent en raison des exceptionnelles 

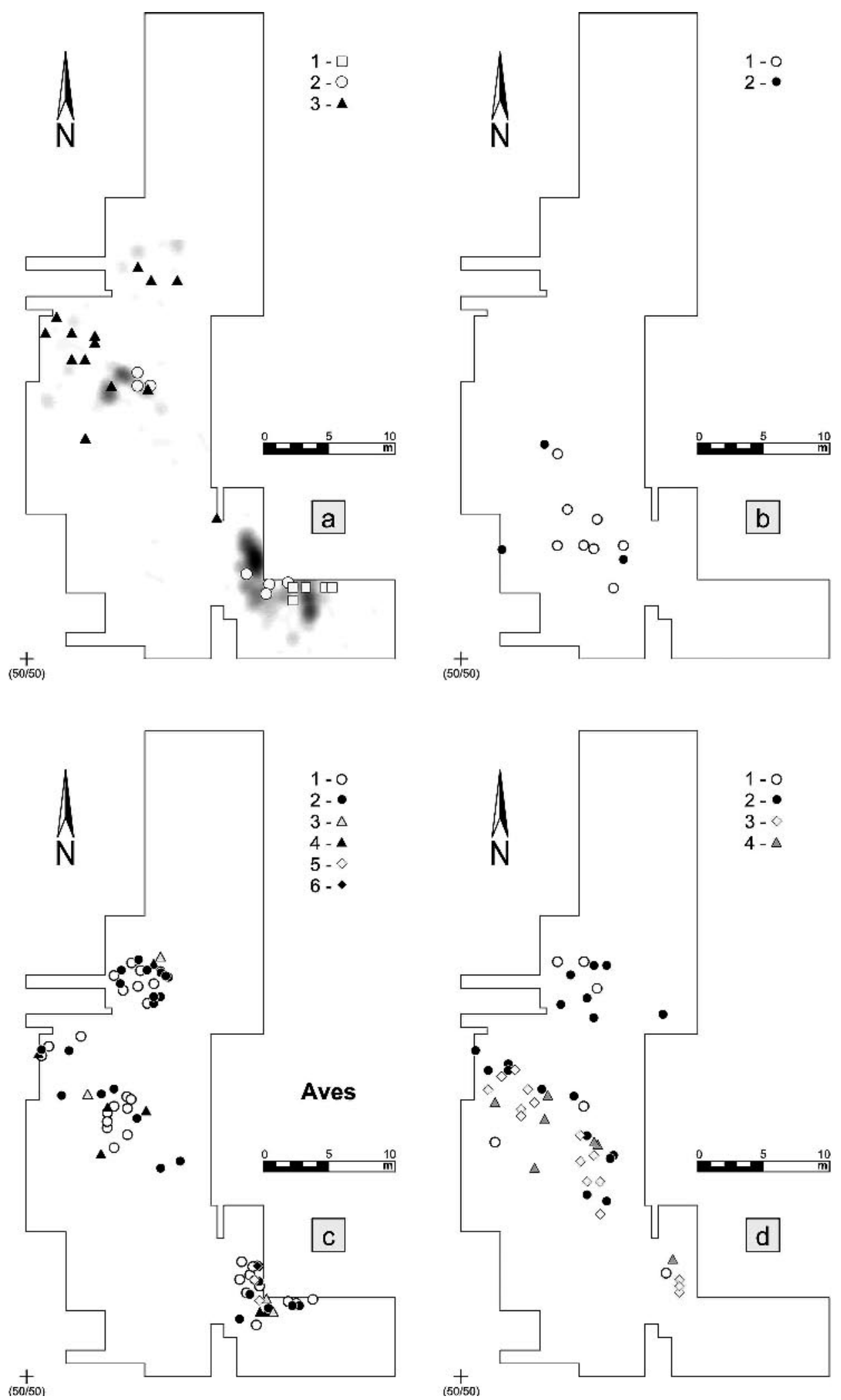

Fig. 11 - Quelques exemples de répartition des vestiges de faune à Gönnersdorf (pour l'emplacement et la dénomination des différentes concentrations, voir fig. 2). a : répartition de l'ivoire de mammouth (carte de densité prenant en compte outils, déchets et fragments); localisation des fragments de molaires de mammouth (1), des os de mammouth (2) et des fragments de maxillaire de rhinocéros laineux (3). Les dates ${ }^{14} \mathrm{C}$ suggèrent que ces deux espèces sont sensiblement plus anciennes que l'occupation principale (voir explications dans le texte). $\mathrm{b}:$ répartition dans le secteur sud-ouest de restes post-crâniens d'attribution tardive appartenant probablement à Cervus elaphus (1) et manifestement à Alces alces (2). c : emplacement des restes d'oiseaux appartenant à des espèces identifiées; restes appartenant à Lagopus sp. (1); à Corvus corax (2); à Cygnus sp. (3); à Anser sp. (4); à Nyctea scandiaca (5); à Larus sp. (6). NB : Les quatre premières espèces apparaissent dans toutes les concentrations de I à III, tandis que les deux dernières ne se retrouvent que dans la concentration I. d : emplacement des restes post-crâniens de Bison/Bos (1) qui se trouvent tous dans la concentration II, à l'exception de deux fragments de côte dans la concentration I et de restes d'origine stratigraphique douteuse dans la concentration IV (non visible ici); dents et fragments de mandibules de Rupicapra rupicapra (2) découverts uniquement dans les concentrations II et III; fragments d'éléments de parure en dents de Cervus elaphus (3) découverts dans la concentration I (6 croches) et dans la concentration II ( 3 incisives sciées); restes post-crâniens de Canis lupus (4) provenant majoritairement de la concentration II (une seule phalange découverte dans la concentration I). 

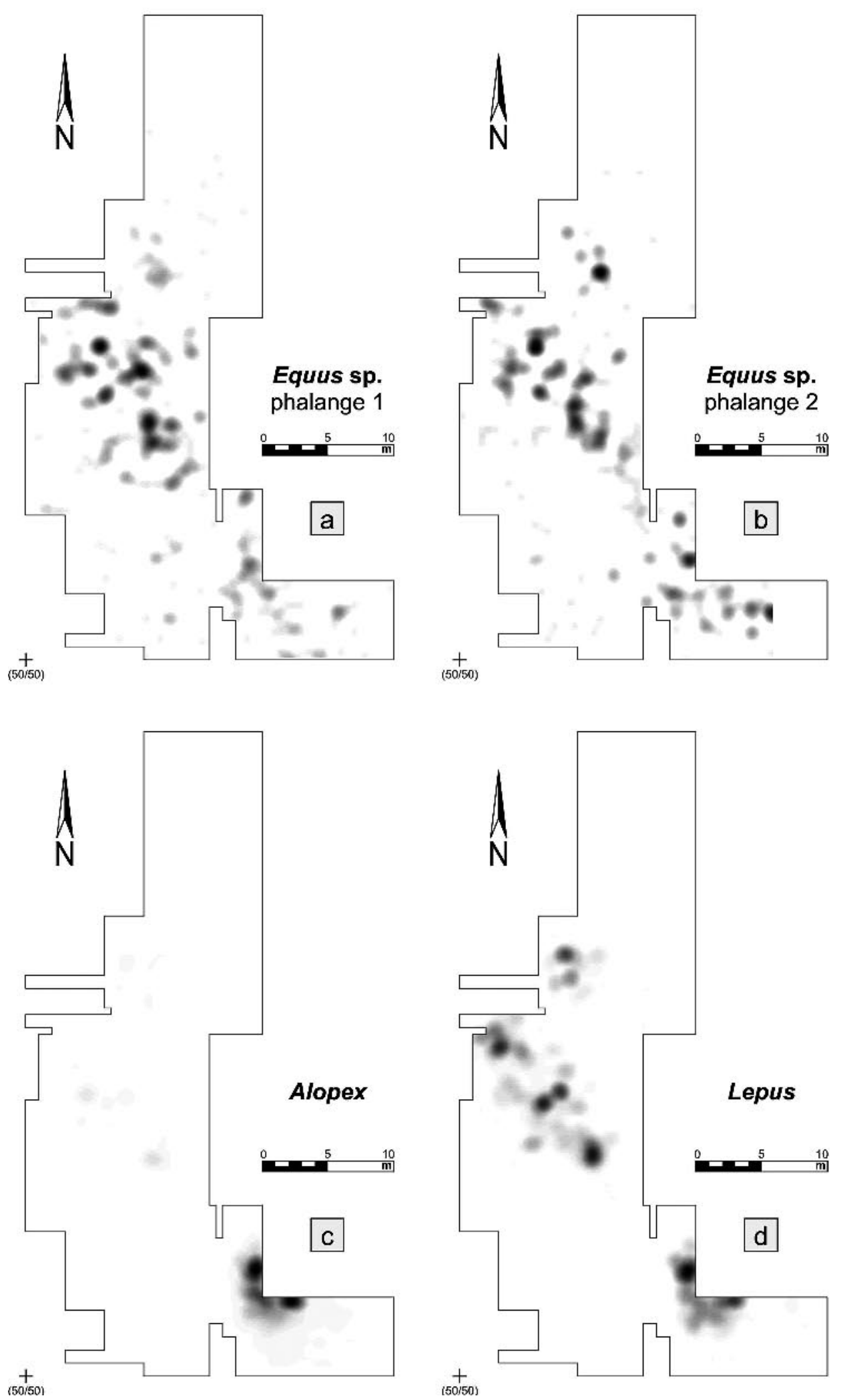

Fig. 12 - Quelques exemples de répartition des vestiges de faune à Gönnersdorf (pour l'emplacement et la dénomination des différentes concentrations, voir fig. 2). a et b : cartes de densité des restes de phalanges 1 et 2 d'Equus sp., éléments du squelette plutôt robustes. La distribution de ces vestiges appartenant à la principale espèce consommée coïncide clairement avec les principales structures d'habitat; on reconnaît aussi leur présence dans le secteur sud-ouest. c et d: cartes de densité des restes post-crâniens d'Alopex lagopus et de Lepus timidus. Les vestiges d'Alopex lagopus sont massivement concentrés au centre de la concentration I, tandis que les vestiges de Lepus timidus ont une distribution plus uniforme dans les concentrations I, II et III, qui ressemblent donc plus à celle des restes d'Equus sp. 
conditions de conservation à Monruz et Champréveyres (Müller et al., ce volume). Au lieu de cela, les indications d'usage du feu à Gönnersdorf se limitent à des traces de rubéfaction thermique dues au feu sur des dalles de pierres et des galets, à une grande quantité de blocs de quartz fissurés au feu (pierres de cuisson?) et à de petites quantités de charbons. Les déchets de taille brûlés ne sont présents qu'en très petit nombre et les os ne montrent presque jamais de trace de brûlure. On en vient à se demander si ce n'était pas des lampes avec du combustible en graisse animale qui fournissaient la lumière et la chaleur plutôt que des foyers.

L'indication la plus claire d'un foyer à Gönnersdorf est la structure de combustion extérieure au nord de la concentration IV (fig. 10), qui consiste en une concentration de blocs de pierre rougis et de quartz fissurés (Terberger, 1997; Moseler, 2006). Au centre de la concentration I, G. Bosinski (1979) interprète aussi comme un foyer une fosse contenant du charbon et du quartz brûlé. On interprète en général l'emplacement des dalles de pierre brûlées comme des emplacements où des feux ont été allumés (Terberger, 1997). Des dalles de pierre brûlées ont également été observées à Andernach (Eickhoff, 1992), mais leur répartition spatiale n'a pas été encore étudiée.

Ainsi, les occupations magdaléniennes de Gönnersdorf et Andernach sont à l'évidence caractérisées par un large spectre d'activités typiques des chasseurscueilleurs. Cela inclut la construction d'une gamme de structures d'habitations qui incorporent de façon diverse des pavages de pierre, le creusement de séries de fosses et l'usage du feu. Ces activités représentent de toute évidence un lourd investissement en temps et en efforts et il paraît clair que les structures découvertes correspondent au dernier état d'un fonctionnement complexe au cours d'une durée appréciable, à différentes époques de l'année et peut-être au cours d'occupations répétées.

Il faut ajouter à cet arrière-plan une accumulation de riches assemblages de vestiges lithiques taillés qui informent d'une part sur les techniques de production et qui, d'autre part, montrent, à travers la gamme des matériaux employés, des déplacements géographiques de grande ampleur. En outre, les remontages permettent de reconstituer l'organisation spatiale des sites et, à cette échelle, les mouvements d'objets et de personnes.

Les vestiges osseux d'espèces variées apportent des informations sur les stratégies de subsistance (le cheval procurant la majeure partie de la viande et de la graisse), mais aussi sur l'utilisation des produits animaux à des fins non alimentaires, comme matières premières pour des outils (bâton percés en bois de renne, pointes de projectile avec ou sans barbelures en bois de renne ou en ivoire, aiguilles à chas en os...), pour des ornements personnels (dents de renard et de renne notamment), ou pour des productions artistiques (ivoire(s ?) sculpté(s ?) et statuettes en bois de renne).

Considérées dans leur ensemble, les structures d'habitat magdaléniennes révèlent un répertoire d'éléments d'habitation standardisé (pavages, fosses...) et l'existence de répartitions spatiales répétitives pour de nombreuses catégories de vestiges (lithiques, faune) à l'intérieur et à l'extérieur des habitations.

De nombreuses dalles de construction en schiste des deux sites sont couvertes de gravures figuratives (Bosinski, 1996; Bosinski et Fischer, 1974 et 1980; Bosinski et al., 2001). Le riche corpus de gravures constitue le pendant des témoignages artistiques des sites en grotte magdaléniens d'Europe de l'Ouest. Les plaques de schiste trouvées à Gönnersdorf et Andernach peuvent être considérées comme une preuve directe des activités sociales complexes qui se sont déroulées dans les sites magdaléniens de Rhénanie centrale.

\section{L'espace social des groupes à Federmesser}

La taille des sites occupés par les groupes à Federmesser reste en gros semblable à celle des gisements magdaléniens et parfois même l'excède de façon spectaculaire (par exemple, tous les locus de Niederbieber considérés ensemble) (fig. 5). Toutefois, l'usage global de l'espace ainsi que les détails des habitations et des autres structures changent radicalement. On ne trouve plus de structures évidentes incorporant de gros éléments de construction (pavage) ni de fosses. Ils sont remplacés par des concentrations lâches et éphémères de vestiges lithiques et de faune qui ne peuvent souvent être identifiées et interprétées qu'à partir d'une analyse détaillée des plans en deux dimensions. Dans certains cas, ces concentrations sont interprétées comme de petites structures couvertes, peut-être des tentes (Gelhausen et al., 2004). D'autres concentrations paraissent refléter une activité à ciel ouvert; d'autres enfin n'ont pas encore été analysées.

Il semble que les groupes à Federmesser aient abandonné la plupart des structures magdaléniennes au profit de formes plus simples d'organisation spatiale. Ceci reflète probablement des durées plus courtes pour chacune des phases de l'occupation d'un site, ce qui entraîne un moindre investissement dans la construction de structures d'habitat stables, coûteuse en temps. Ce phénomène est bien connu et on l'attribue souvent à une plus forte mobilité résidentielle liée au changement d'environnement durant cette phase interstadiaire.

Ce qui est très visible, ce sont les changements dans la façon d'utiliser le feu. En témoigne l'apparition de foyers incontestables qu'on peut parfois reconnaître grâce à l'altération thermique du sédiment sous-jacent (rubéfaction, cuisson). Mais ils sont le plus souvent identifiés par des concentrations discrètes de vestiges lithiques et fauniques brûlés, ou de charbons, de quelque 50 à $80 \mathrm{~cm}$ de diamètre, qui sont souvent au centre d'aires de vestiges non brûlés interprétées comme le lieu des diverses activités de l'habitat (fig. 13). Les vastes quantités de matériel brûlé trouvé dans les sites à Federmesser suggèrent que toutes sortes de déchets arrivaient facilement jusque dans des foyers aisément accessibles. Cet état de fait est révélateur d'un comportement différent de celui qui présidait aux activités des habitats magdaléniens, où l'usage du feu 

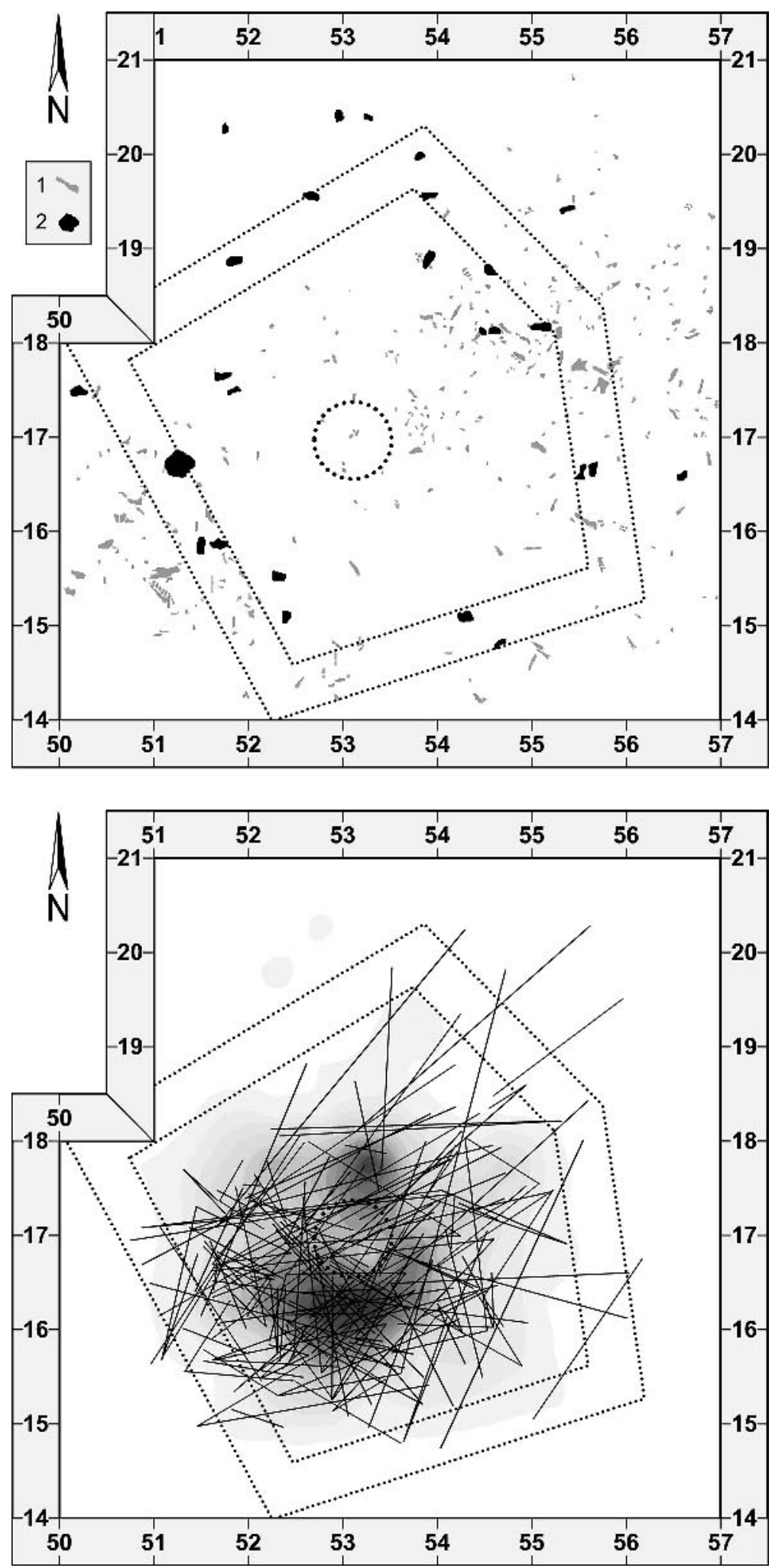

Fig. 13 - La concentration IV à Niederbieber. En haut : répartition autour d'un foyer central des os et des dents (1) ainsi que des manuports de plus grande dimension (2). La plupart des éléments volumineux se trouvent en périphérie de la zone qui accueille la majorité des artefacts lithiques. En bas : carte de densité des artefacts lithiques et liaisons établies par remontages. 
semble avoir été bien plus contrôlé, peut-être en raison de la rareté du combustible ou de la nécessité de confiner les feux plus soigneusement à l'intérieur de structures encloses. On revient à cette hypothèse concernant le Magdalénien selon laquelle lumière et même chaleur pourraient provenir de lampes utilisant de la graisse animale.

On peut distinguer deux grandes catégories de campements des groupes à Federmesser. Le premier est attesté à Andernach 2 (AN2 FMG), à Niederbieber (NiBi II) et à Kettig. Il se caractérise par une grande hétérogénéité des trouvailles (des matières lithiques diverses ainsi que des animaux chassés variés) et par un usage de l'espace peu centralisé. Lorsqu'il existe des indices de saisonnalité, il s'agit d'occupations d'été ou d'automne.

Ainsi, l'horizon à Federmesser d'Andernach 2 (AN2 FMG) est caractérisé par une concentration généralement diffuse de matériel lithique et faunique située dans la partie centrale de la partie fouillée du site. Des concentrations plus ou moins discrètes de vestiges lithiques semblent correspondre à des aires de taille ou peut-être à des rejets de déchets de taille, parfois en liaison les uns avec les autres à travers le site. Certains remontages d'os s'étalent également sur près de $10 \mathrm{~m}$, montrant ainsi que les activités de boucherie et de rejet des déchets osseux prenaient place sur l'ensemble de l'espace occupé, sans qu'on trouve de carcasses bien individualisées à des endroits précis. La mise sur plan des charbons, des vestiges lithiques et osseux brûlés, des pierres à cuire en quartz rubéfiées et fissurées a conduit à l'identification probable de quatre foyers. Les espèces de bois brûlées sont variées et incluent du saule, du pin et du bouleau, chacune connaissant une répartition légèrement différente au sein des accumulations de charbons. Les séries de vestiges lithiques et d'os remontés comprennent également des éléments brûlés, qui, dans certains cas, sont présents au milieu des vestiges non brûlés, ce qui implique qu'ils ont été brûlés sur place plutôt que rejetés dans un dépotoir. À Andernach 2, on peut identifier une structure close (tente?) en appliquant la méthode des «Rings and Sectors» (Stapert et Street, 1997). Il est maintenant possible de réexaminer ces résultats en utilisant d'autres analyses, telles que la production de plans de densité pour tous les vestiges de cette partie du site.

Le site Niederbieber II (NiBi II) est similaire à AN2FMG en dimension et en organisation spatiale et il présente la même variété de vestiges (lithiques taillés, faune, charbons) et de structures (aires de taille et de rejet, aires de combustion, etc.) (Loftus, 1985). Mais à la différence d'Andernach, les épisodes de combustion étaient aisément reconnaissables durant la fouille de $\mathrm{NiBi}$ II en raison de l'altération thermique du sédiment intensément rubéfié. Cette rubéfaction était parfois très localisée et altérait le sédiment en profondeur, donnant à croire à un foyer en fosse. Dans d'autres cas, elle était parfois très superficielle, mais sur une large surface. Peut-être s'agissait-il alors de la combustion (accidentelle?) d'une zone beaucoup plus étendue. NiBi II se trouve au nord-est du site de Niederbieber, assez loin de la majorité des autres concentrations fouillées, et il serait intéressant d'explorer le site plus largement à l'avenir dans cette zone.

Le site de Kettig a aussi livré des vestiges de foyers associés à du matériel brûlé incluant quelques charbons de bois (avec peuplier dominant), des éléments lithiques, des quartz et des ossements brûlés (Baales, 2002). Quelques outils présentent des traces d'emmanchement sous forme de résine à base d'écorce de bouleau distillée, laissant penser que ce produit était utilisé pour la réfection de l'outillage, s'il ne l'était pas pour sa production sur place.

Le second type d'organisation spatiale est représenté à Niederbieber (NiBi I, NiBi IV), Andernach 3 (AN3 FMG), Bad Breisig et peut-être dans un nombre non spécifié d'autres concentrations de Niederbieber. Il se caractérise par une concentration discrète de vestiges autour d'un foyer, qui est dominée par une seule sorte de matière première lithique et une espèce de faune dominante. Ceux des sites pour lesquels la saison d'occupation est connue ont été fréquentés en automne/ hiver.

$\mathrm{NiBi}$ I et NiBi IV se trouvent au sud-est du site et sont tout à fait semblables. De nombreux remontages de vestiges lithiques relient ces deux concentrations. L'interprétation en a changé en fonction des méthodes d'analyse. Les deux concentrations ont d'abord été interprétées comme des aires d'activités autour de foyers (Bolus, 1992). La poursuite des analyses conduit aujourd'hui à penser que ces structures sont en fait des habitations, peut-être de petites tentes (Gelhausen et al., 2004) (fig. 13). Deux foyers associés à des outils de calcédoine et des concentrations d'os sont présents à Andernach (AN3 FMG) et ce site est interprété comme un habitat similaire à NiBi I et NiBi IV (Gelhausen et al., 2004).

La répartition spatiale des trouvailles à Bad Breisig est conforme à ce type de site, avec un foyer central contenant des charbons de pin, entouré par une concentration à forte densité de vestiges lithiques ainsi que par quelques restes fauniques (Grimm, 2003 et 2004). On peut déjà interpréter l'organisation spatiale à Boppard comme centrée sur un foyer, bien qu'une analyse fine du site reste à réaliser.

À Urbar, il ne reste aucune trace d'un foyer en dépit de la présence de charbons ( $89 \%$ de saule ainsi que du bouleau et du pin) qui indique que l'usage du feu faisait partie des activités pratiquées sur le site (Baales et al., 1998). L'interprétation du site reste difficile en raison de la faible surface fouillée et d'une absence de différenciation spatiale nette. Il n'est pas possible de décider s'il y avait une habitation ou non. Mais il est probable qu'il s'agisse d'un campement d'automne/hiver lié à la chasse au cerf, présent en grand nombre et presque exclusif parmi les restes osseux. Le très grand nombre de grattoirs fait penser, par analogie avec les autres sites, que le travail des peaux de cerf a pu jouer un grand rôle. Urbar pourrait alors être quelque chose comme un campement spécialisé dans la chasse et le traitement de ses produits.

$\mathrm{NiBi}$ III ne rentre pas dans les catégories de cet hypothétique modèle bipartite et se présente comme un ensemble particulier, installé dans une petite 
paléovallée éloignée de la zone d'occupation principale (Bosinski et al., 1982). Ce pourrait être une petite aire d'activité localisée et peut-être spécialisée. Des charbons et des vestiges lithiques brûlés démontrent l'usage $\mathrm{du}$ feu dans cette aire, tandis que les restes osseux y sont rares (Equus, Castor). Un élément original de $\mathrm{NiBi}$ III consiste en un groupe de cinq retouchoirs en pierre, certains encore neufs, qui constituent peut-être une cache ou qui devaient être ultérieurement utilisés pour de la réfection d'outillage sur place.

En général, la gamme des vestiges archéologiques et la variété des activités observées dans les sites des groupes à Federmesser de Rhénanie sont moins diversifiées que dans les sites magdaléniens. Presque tous les objets mis au jour sont liés soit à la production d'outils lithiques, soit à des activités de subsistance qu'on peut déduire des restes provenant de la découpe de mammifères et d'autres espèces. Ces deux catégories d'activités semblent s'être déroulées de façon courante dans le voisinage de foyers non protégés et donc facilement accessibles.

On ne trouve plus la grande variété des objets manufacturés en matière organique des sites magdaléniens (pointes de projectiles, bâtons percés, aiguilles, retouchoirs etc.); les rares exceptions sont un harpon à Kettig et un fragment modifié et décoré de métapode de cerf trouvé à Boppard (Wenzel, 2004; Wenzel et Àlvarez Fernàndez, 2004) (fig. 6). De même, les objets de parure sont quasiment inconnus dans les sites à Federmesser de Rhénanie. Les exceptions sont une incisive de cerf incisée trouvée à Andernach (AN2 FMG) et une incisive incisée et perforée de NeuwiedIrlich (Baales, 2002), qui est probablement un peu antérieure à la phase à Federmesser.

Comme on l'observe de façon générale au Paléolithique final à travers toute l'Europe, les groupes à Federmesser de Rhénanie se caractérisent par un déclin et une raréfaction notables de l'expression artistique, associés à un passage du réalisme à l'abstraction. On ne trouve pratiquement ni art abstrait ni art figuratif en Rhénanie à cette période, à l'exception de quelques fragments de dalles gravées de quelques lignes au plus, et qui pourraient même résulter de l'emploi de ces dalles comme surfaces de découpe.

Parmi les exceptions, il y a la série de figures schématiques gravées sur le bord d'un polissoir de grès de NiBi II à Niederbieber (Loftus, 1982). Ces gravures ont une ressemblance inattendue avec les représentations féminines abstraites caractéristiques du Magdalénien. Elles pourraient témoigner d'une certaine continuité conceptuelle d'une période à l'autre, en dépit des autres changements radicaux concernant l'environnement, les ressources alimentaires et des techniques complètement transformées.

Enfin, un galet de schiste récemment trouvé dans champ labouré de la vallée de la rivière Sieg montre d'anciennes traces d'utilisation comme retouchoir et comme surface de découpe (Heuschen et al., 2006). Il ressemble beaucoup aux retouchoirs des sites à Federmesser du bassin de Neuwied, à $60 \mathrm{~km}$ au sud. Plus important, la pièce en question porte des gravures animales sur les deux faces (fig. 6) et, à ce jour, les plus proches parallèles sont à chercher dans les retouchoirs gravés ou autres galets des sites du Paléolithique supérieur ou final d'Europe de l'Ouest (Lorblanchet, 1989). Les gravures semblent représenter un élan et l'on peut mentionner l'élan sculpté en ambre de Weitsche dans un contexte analogue.

\section{DISCUSSION ET CONCLUSIONS : ESSAI DE SYNTHËSE ET COMPARAISONS ENTRE MAGDALENIEN ET GROUPES À FEDERMESSER}

Les changements dans les modes de subsistance entre le Magdalénien et les occupations à Federmesser en Rhénanie centrale se sont accompagnés de transformations radicales dans les techniques, dans l'organisation spatiale interne des habitats et dans les manifestations artistiques. Il est fort possible que ces changements soient dus en partie aux transformations affectant les ressources dès le commencement de la phase interstadiaire.

Les sites magdaléniens de la Rhénanie centrale ont généralement été interprétés comme des camps de base majeurs caractérisés par une gamme complète d'activités techniques, économiques et sociales et, de façon générale, cette hypothèse tient toujours. On a suggéré que des habitats de ce type devaient probablement se trouver au centre d'un réseau de campements satellites spécialisés (tels que des haltes de chasse ou de cueillette) et être approvisionnés par ces derniers, mais il n'a jamais été trouvé de site magdalénien de ce type en Rhénanie centrale. Une telle structuration de l'environnement n'existait peut-être pas et n'était peut-être même pas nécessaire. Il est clair désormais que les groupes magdaléniens pouvaient être présents et survivre dans le bassin de Neuwied à différents moments de l'année.

Toutefois, des sites d'Allemagne du Sud tels que Petersfels et Schussenquelle et d'autres dans le Nord et l'Est de la France (Pincevent ou Solutré par exemple) démontrent l'existence de campements beaucoup plus spécialisés dans les régions voisines. Dans de nombreux cas, on peut les associer à la chasse au renne, notamment en automne, et il n'est pas impossible que les occupations d'automne et d'hiver de Gönnersdorf et d'Andernach aient reçu leurs ressources alimentaires de camps de ce type, qui restent cependant à découvrir.

Une hypothèse alternative pourrait consister à reconnaître que ces occupations sont le résultat d'une plus grande capacité d'adaptation et de flexibilité. En effet, les différentes concentrations ne représentent pas des phénomènes identiques et il est probable que la fonction précise d'une concentration pouvait connaître des transformations dynamiques à travers le temps, en fonction de la saison d'occupation, de la taille du groupe, de la durée d'occupation, etc. L'habitat notablement plus récent de Gönnersdorf SW répondait probablement à des facteurs environnementaux fort différents de la phase d'occupation principale, tandis qu'à Andernach le même emplacement a été occupé 
par les Magdaléniens et les groupes à Federmesser de façon complètement différente. Un même phénomène a été récemment observé à Pincevent où on est passé d'une longue tradition de camps de chasse au renne d'automne à un habitat d'hiver avec une faune variée (Julien, ce volume).

L'apparition des groupes à Federmesser coïncide avec l'établissement d'un paysage forestier ouvert. Le gibier accessible pour ces groupes était présent en moindre densité et était probablement plus uniformément réparti dans cet environnement de plus en plus boisé. Il est probable que ce facteur, allié à la disparition des ressources saisonnières prévisibles que constituent les espèces migratoires, et en particulier le renne, a conduit à accroître la mobilité humaine sur le court terme. Il est toutefois possible que certains des assemblages dominés par le cerf, le plus souvent constitués en automne-hiver, attestent que la chasse était ciblée sur cette espèce au moment du regroupement lié au rut, ou durant l'hiver quand la couverture de neige conduit les cerfs à paître dans des aires qu'ils maintiennent déneigées.

L'adaptation à une base économique transformée s'est accompagnée d'un changement complet de la technologie et de la typologie lithique - en particulier des types d'armes de chasse. L'adoption de l'arc et des flèches est sans doute une réaction à la chasse en milieu forestier, peut-être avec l'aide de chiens (présents en Rhénanie au plus tard à partir de l'époque de BonnOberkassel) pour suivre dans les sous-bois la piste ensanglantée des animaux blessés par les traits et aboyer après le gibier.

L'organisation des sites à Federmesser se caractérise par la disparition des grandes structures d'habitat stables et occupées à plusieurs reprises, et par l'apparition de structures plus petites et éphémères telles qu'on les rencontre à plusieurs reprises dans l'horizon supérieur d'Andernach, à Bad Breisig, Kettig, Niederbieber, Boppard et Urbar. Ces transformations dans les types d'habitation et la structuration de l'habitat reflètent probablement la durée plus brève des occupations et pourraient également suggérer des changements dans l'organisation sociale (taille des familles, du groupe, etc.).

Dans l'ensemble, les changements observés dans le mode de subsistance, les techniques, les types d'habitations et l'organisation des habitats ont agi en interaction, conduisant à une mobilité accrue et à une réduction de la durée de résidence dans tous les sites. Ces changements dans l'organisation matérielle de la vie quotidienne et des cycles annuels de nomadisation ont pu aussi entraîner les changements que l'on constate d'une période à l'autre dans les expressions esthétiques et artistiques. Le développement du Paléolithique final annonce le mode de vie du Mésolithique dans l'Europe holocène.

\section{NOTE}

Article traduit depuis l'anglais par Françoise Audouze, Magen O'Farrell et Boris Valentin.

\section{RÉFÉRENCES BIBLIOGRAPHIQUES}

ÁLVAREZ FERNÁNDEZ E. (2001) - L'axe Rhin-Rhône au Paléolithique supérieur récent : l'exemple des mollusques utilisés comme objets de parure, L'Anthropologie, t. 105, p. 547-564.

BAALES M. (2002) - Der spätpaläolithische Fundplatz Kettig. Untersuchungen zur Siedlungsarchäologie der Federmesser-Gruppen am Mittelrhein, Monographien des Römisch-Germanischen Zentralmuseums Mainz, 51, Mainz.

BAALES M. (2003) - Zur Fortführung der Ausgrabungen auf dem spätpaläolithischen Siedlungsareal von Niederbieber (Stadt Neuwied). Erste Ergebnisse der siedlungsarchäologischen Analyse, Jahrbuch des Römisch-Germanischen Zentralmuseums Mainz, 48 (1), 2001, p. 163198.

BAALES M., JÖRIS O. (2001) - Zwischen Nord und Süd. Ein spätallerodzeitlicher Rückenspitzen-Fundplatz bei Bad Breisig, Kr. Ahrweiler (Mittelrhein, Rheinland-Pfalz), Die Kunde N. F., 52, p. 275-292.

BAALES M., JÖRIS O. (2002) - Entre le nord et le sud - un site à pointes à dos de la fin de 1'Allerød : Bad Breisig, district de Ahrweiler (vallée moyenne du Rhin, RFA), L'Anthropologie, t. 106(2), p. 249-267.

BAALES M., STREET M. (1998) - Late Palaeolithic Backed-Point assemblages in the northern Rhineland: current research and changing views, Notae Praehistoricae, 18, p. 77-92.

BAALES M., MEWIS S.U., STREET M. (1998) - Der FedermesserFundplatz Urbar bei Koblenz (Kreis Mayen-Koblenz), Jahrbuch des Römisch-Germanischen Zentralmuseums Mainz, 43 (1) (1996), p. 241279.

BAALES M., GRIMM S., JÖRIS O. (2001) - Hunters of the «Golden Mile». The late Allerød Federmessergruppen site at Bad Breisig, Central Rhineland, Germany, Notae Praehistoricae, 21, p. 67-72.
BAALES M., JÖRIS O., STREET M., BITTMANN F., WENINGER B., WIETHOLD J. (2002) - Impact of the Late Glacial eruption of the Laacher See volcano, Central Rhineland, Germany, Quaternary Research, 58, p. 273-288.

BERGMANN S. (1999) - Die Gruben 1-3 des Magdalénienfundplatzes Andernach-Martinsberg, Grabung 1994-1996, M.A. thesis, University of Cologne.

BERGMANN S., HOLZKÄMPER J. (2002) - Die Konzentration IV des Magdalénien von Andernach-Martinsberg, Grabung 1994-1996. Erste Ergebnisse, Archäologisches Korrespondenzblatt, 32(4), p. 471-486.

BOLUS M. (1992) - Die Siedlungsbefunde des späteiszeitlichen Fundplatzes Niederbieber (Stadt Neuwied). Ausgrabungen 1981-1988, Monographien des Römisch-Germanischen Zentralmuseums Mainz, 22, Bonn.

BOLUS M., STREET M. (1985) - 100 Jahre Eiszeitforschung am Martinsberg in Andernach, Archäologisches Korrespondenzblatt, $15(1)$, p. $1-9$

BOSINSKI G. (1970) - Der Magdalénien-Fundplatz Feldkirchen-Gönnersdorf, Kreis Neuwied. Vorbericht über die Ausgrabungen 1968, Germania, 47 (1969), p. 1-38.

BOSINSKI G. (1979) - Die Ausgrabungen in Gönnersdorf 1968-1976 und die Siedlungsbefunde der Grabung 1968. Der Magdalénien-Fundplatz Gönnersdorf, 3, Wiesbaden.

BOSINSKI G. (1996) - Die Gravierungen des Magdalénien-Fundplatzes Andernach-Martinsberg, Jahrbuch des Römisch-Germanischen Zentralmuseums Mainz, 41 (1994), p. 19-58.

BOSINSKI G., BOSINSKI H. (1991) - Robbendarstellungen von Gönnersdorf, in A. Aktas et W. Boenigk dir., Festschrift Karl Brunnacker Sonderveröffentlichungen des geologischen Instituts Köln, p. 81-87. 
BOSINSKI G., FISCHER G. (1974) - Die Menschendarstellungen von Gönnersdorf der Ausgrabung 1968. Der Magdalénien-Fundplatz Gönnersdorf, 1, Wiesbaden.

BOSINSKI G., FISCHER G. (1980) - Mammut- und Pferdedarstellungen von Gönnersdorf. Der Magdalénien-Fundplatz, Gönnersdorf, 5 , Wiesbaden.

BOSINSKI G., HAHN J. (1972) - Der Magdalénien-Fundplatz Andernach (Martinsberg), Rheinische Ausgrabungen, 11, Cologne et Bonn, p. $81-257$.

BOSINSKI G., BRAUN R., TURNER E., VAUGHAN P. (1982) - Ein spätpaläolithisches Retuscheurdepot von Niederbieber/Neuwieder Becken, Archäologisches Korrespondenzblatt, 12(3), p. 295-311.

BOSINSKI G., D'ERRICO F., SCHILLER P. (2001) - Die gravierten Frauendarstellungen von Gönnersdorf. Der Magdalénien-Fundplatz Gönnersdorf, 8, Stuttgart.

BUSCHKÄMPER T. (1993) - Die Befunde im Südwestteil der Gönnersdorfer Grabungsfäche, M.A. thesis, University of Cologne.

EICKHOFF S. (1988) - Die Artefakte aus westeuropäischem Feuerstein des Magdalénien-Fundplatzes Gönnersdorf, M.A. thesis, University of Cologne.

EICKHOFF S. (1992) - Wohnplatzstrukturen: Strukturierung eines Wohnplatzes. Zur Besiedlungsgeschichte des Magdalénien-Fundplatzes Andernach, Ph. D. thesis, University of Cologne.

EIDEN H., LÖHR H. (1974) - Der endpaläolithische Fundplatz Urbar, Kreis Mayen-Koblenz (Rheinland-Pfalz), Archäologische Informationen, 2-3 (1973-1974), p. 45-46.

FLOSS H. (1994) - Rohmaterialversorgung im Paläolithikum des Mittelrheingebietes, Monographie des Römisch-Germanischen Zentralmuseum, 21, Bonn.

FLOSS H., TERBERGER T. (2002) - Die Steinartefakte des Magdalénien von Andernach (Mittelrhein). Die Grabungen 1979-1983, Herrn Prof. Dr. Gerhard Bosinski zum 65. Geburtstag, Tübinger Arbeiten zur Urgeschichte, 1, Rahden (Westf.)

FREERICKS M. (1989) - Der Fundplatz Niederbieber. Fläche 17/4622/52, M.A. thesis, University of Cologne.

FREERICKS M. (1991) - Die Fläche VII (17/46-22/52) des späteiszeitlichen Fundplatzes Niederbieber, Archäologisches Korrespondenzblatt, 21(3), p. 343-350.

FRIEDRICH M., REMMELE S., KROMER B., HOFMANN J., SPURK M., KAISER K.F., ORCEL C., KÜPPERS M. (2005) - The 12,460 year Hohenheim oak and pine tree-ring chronology from central Europe - a unique annual record for radiocarbon calibration and paleoenvironment reconstructions, Radiocarbon, 46(3) (2004), p. 1111-1122.

GELHAUSEN F. (en préparation) - Die innere Struktur von Fundkonzentrationen und ihre Beziehungen zueinander - Untersuchungen zum Siedlungsmuster der allerødzeitlichen Federmessergruppen in Niederbieber, Stadt Neuwied, Rheinland-Pfalz, Ph.D. thesis, University of Cologne.

GELHAUSEN F., KEGLER J., WENZEL S. (2004) - Latent dwelling structures in the Final Palaeolithic: Niederbieber IV, AndernachMartinsberg 3, Berlin-Tegel IX, Notae Praehistoricae, 24, p. 69-79.

GRIMM S. (2003) - Der spätpaläolithische Fundplatz bei Bad Breisig/ Kreis Ahrweiler, M.A. thesis, University of Cologne.

GRIMM S. (2004) - Ein spätallerödzeitlicher Fundplatz bei Bad Breisig, Kreis Ahrweiler, Berichte zur Archäologie an Mittelrhein und Mosel, 9, Koblenz, p. 11-32.

GUTHRIE R.D. (1982) - Mammals of the mammoth steppe as palaeoenvironmental indicators, in D.M. Hopkins, J.V. Matthews, C.S. Schweger et S.B. Young dir., Palaeoecology of Beringia, Academic Press, New York, London, p. 307-326.

HEUSCHEN W. (1997) - Die Artefakte aus paläozoischem Quarzit von Gönnersdorf und Andernach, M.A. thesis, University of Cologne.
HEUSCHEN W., GELHAUSEN F. GRIMM S.B., STREET M. (2006) - Ein verzierter Retuscheur aus dem mittleren Siegtal (Nordrhein-Westfalen), Archäologisches Korrespondenzblatt, 36(1), p. 1728 .

HÖCK C. (1995) - Die Frauenstatuetten von Gönnersdorf und Andernach, Jahrbuch des Römisch-Germanischen Zentralmuseums Mainz, 40 (1993), p. 253-316.

HÖRTER P. (1928) - Der Kreis Mayen in ur- und frühgeschichtlicher Zeit, Mayen.

HOLZKÄMPER J. (1999) - Die retuschierten Steinartefakte des Magdalénien von Andernach-Martinsberg, Grabung 1994-1996, M.A. thesis, University of Cologne.

HOUSLEY R.A., GAMBLE C.S., STREET M., PETTITT P. (1997) Radiocarbon evidence for the Lateglacial human recolonisation of Northern Europe, Proceedings of the Prehistoric Society, 63, p. 2554.

HUSMANN H. (1988) - Die Fläche 37/40-42/45 des späteiszeitlichen Fundplatzes Niederbieber/Neuwieder Becken, M.A. thesis, University of Cologne.

HUSMANN H. (1989) - Die Konzentration V (Fläche 37/40-42/45) des späteiszeitlichen Fundplatzes Niederbieber. Neu Erkenntnisse zur internen Chronologie, Archäologisches Korrespondenzblatt, 19(2), p. $117-127$

JÖRIS O., TERBERGER T. (2001) - Zur Rekonstruktion eines Zeltes mit trapezförmigem Grundriß am Magdalénien-Fundplatz Gönnersdorf/Mittelrhein - eine «Quadratur des Kreises»?, Archäologisches Korrespondenzblatt, 31(2), p. 163-172.

JOHNSEN S.J., DAHL-JENSEN D., GUNDESTRUP N., TEFFENSEN J.P., CLAUSEN H.B., MILLER H., MASSON-DELMOTTE V., SVEINBJÖRNSDOTTIR A.E., WHITE J. (2001) - Oxygen isotope and paleotemperature records from six Greenland ice-core stations: Camp-Century, Dye-3, GRIP, GIPS2, Renland and NorthGRIP, Journal of Quaternary Science, 16(4), p. 299-307.

KEGLER J.F. (1999) - Die retuschierten Steinartefakte der Oberen Fundschicht von Andernach-Martinsberg, Grabung 1994-1996, M.A. thesis, University of Cologne.

KEGLER J.F. (2002) - Die federmesserzeitliche Fundschicht des paläolithischen Siedlungsplatzes Andernach-Martinsberg, Grabung 1994 1996, Archäologisches Korrespondenzblatt, 32(4), p. 501-516.

LITT T., STEBICH M. (1999) - Bio- and chronostratigraphy of the lateglacial in the Eifel region, Germany, Quaternary International, 61, p. 5-16.

LOFTUS J. (1982) - Ein verzierter Pfeilschaftglätter von Fläche 64/7073/78 des spätpaläolithischen Fundplatzes Niederbieber/Neuwieder Becken, Archäologisches Korrespondenzblatt, 12(3), p. 313-316.

LOFTUS J. (1985) - Der spätpaläolithische Fundplatz Niederbieber, Fläche 64/74-81/77, M.A. thesis, University of Cologne.

LOFTUS R. (1984) - Der spätpaläolithische Fundplatz Niederbieber, Fläche 33/32-38/39, M.A. thesis, University of Cologne.

LORBLANCHET M. (1989) - De l'art naturaliste des chasseurs de rennes à l'art géométrique du Mésolithique dans le Sud de la France, Revista de Cultura, 7, p. 95-124.

MOSELER F. (2006) - Die Konzentration IV des MagdalénienFundplatzes Gönnersdorf (Mittelrhein). Eine räumliche Analyse der Steinartefakte, M.A. thesis, Johannes Gutenberg University of Mainz.

POPLIN F. (1972) - Die Großfauna, in G. Bosinski et J. Hahn, Der Magdalénien-Fundplatz Andernach (Martinsberg), Rheinische Ausgrabungen 11 , p. 175-191.

POPLIN F. (1976) - Les grands vertébrés de Gönnersdorf. Fouilles 1968. Der Magdalénien-Fundplatz Gönnersdorf, 2, Wiesbaden.

SCHAAFFHAUSEN H. (1888) - Die vorgeschichtliche Ansiedelung in Andernach, Bonner Jahrbücher, 86, p. 1-41. 
SENSBURG M. (2004) - Die Untersuchung der Siedlungsstrukturen der Konzentration II von Gönnersdorf, Ph.D. thesis, University of Cologne.

SIROCKO F., SEELOS K., SCHABER K., REIN B., DREHER F., DIEHL M., LEHNE R., JÄGER K., KRBETSCHEK M., DEGERING D. (2005) - A late Eemian aridity pulse in central Europe during the last glacial inception, Nature, 436, p. 833-836.

STAPERT D., STREET M. (1997) - High resolution or optimum resolution? Spatial analysis of the Federmesser site at Andernach, Germany, World Archaeology, 29, p. 172-194.

STREET M. (1993) - Analysis of Late Palaeolithic and Mesolithic Faunal Assemblages in the Northern Rhineland, Germany, Ph.D. thesis, University of Birmingham.

STREET M., BAALES M., CZIESLA E., HARTZ S., HEINEN M., JÖRIS O., KOCH I., PASDA C., TERBERGER T., VOLLBRECHT J. (2002) - Final Paleolithic and Mesolithic research in reunified Germany, Journal of World Prehistory, 15 (2001) (4), p. 365-453.

TERBERGER T. (1997) - Die Siedlungsbefunde des MagdalénienFundplatzes Gönnersdorf. Konzentrationen III und IV. Der Magdalénien-Fundplatz Gönnersdorf, 6, Stuttgart.

THOMAS R. (1990) - Der spätpaläolithische Fundplatz, Niederbieber/ Stadt Neuwied. Fläche 7/30-11/34, M.A. thesis, University of Cologne.

TINNES J. (1994) - Die Geweih-, Elfenbein- und Knochenartefakte der Magdalénienfundplätze Gönnersdorf und Andernach, Ph.D. thesis, University of Cologne.

VEIL S. (1978) - Neue Untersuchungen auf dem Magdalenien-Fundplatz Martinsberg in Andernach, Trierer Zeitschrift, 40/41 (1977/1978), p. 9-40.

VEIL S. (1979) - Neue Ausgrabungen auf dem Magdalénien-Fundplatz Andernach-Martinsberg (Rheinland-Pfalz), Archäologisches Korrespondenzblatt, 9(3), p. 251-260.

VEIL S. (1982a) - Der späteiszeitliche Fundplatz Andernach, Martinsberg, Germania, 60(2), p. 391-424.

VEIL S. (1982b) - Structures d'habitat du Magdalénien d'Andernach RFA, Les habitats du Paléolithique supérieur, Colloque international Roanne-Villerest, 1982, p. 229-232.
VEIL S. (1984) - Siedlungsbefunde vom Magdalénien-Fundplatz Andernach (Zwischenbericht über die Grabungen 1979-1983), in H. Berke, J. Hahn et C.J. Kind dir., Jungpaläolithische Siedlungsstrukturen in Europa, Urgeschichtliche Materialhefte, 6, Tübingen, p. 181-193.

WENINGER B., JÖRIS J. (2004) - Glacial Radiocarbon Age Calibration: the CalPal Program, in T. Higham, Chr. Bronk Ramsey et C. Owen dir., Radiocarbon and Archaeology, Fourth International Symposium, St. Catherine's College, Oxford, 9-14 April 2002, Oxford University School of Archaeology Monograph, 62, Oxford, p. $9-15$.

WENZEL S. (2004) - Ein verziertes Knochengerät spätaltsteinzeitlicher Hirschjäger aus Boppard, Rhein-Hunsrück-Kreis, Archäologie in Rheinland-Pfalz (2003), Mainz, p. 13-15.

WENZEL S., ÁLVAREZ FERNÁNDEZ E. (2004) - La espátula de Boppard (Boppard, Renania-Palatinado, Alemania) y sus paralelos en Europa a finales del paleolítico superior y en el mesolítico, Zephyrus, 57, Salamanca, p. 137-151.

WINTER D. (1986) - Der spätpaläolithische Fundplatz, Niederbieber, Fläche 50/14-56/20, M.A. thesis, University of Cologne.

Martin STREET (street@rgzm.de)

Frank GELHAUSEN (gelhausen@rgzm.de)

Sonja GRIMM (grimm@ rgzm.de)

Frank MOSELER (frank_moseler@hotmail.com)

Laura NIVEN (niven@rgzm.de)

Martina SENSBURG (sensburg@ rgzm.de)

Elaine TURNER (turner@rgzm.de)

Stefan WENZEL (wenzel@rgzm.de)

Olaf JÖRIS (joeris@ rgzm.de)

Römisch-Germanisches Zentralmuseum Forschungsbereich Altsteinzeit Schloss Monrepos D-56567 Neuwied, Germany 